Visual Perspective Taking

\title{
Visual perspective taking in young and older adults
}

Martin, A.K. ${ }^{1}$, Perceval, G. ${ }^{1}$, Davies, I. ${ }^{1,2}$, Su, P., Huang, J. ${ }^{1}$, \& Meinzer, M $^{1}$.

${ }^{1}$ University of Queensland, Centre for Clinical Research, Brisbane, Australia

${ }^{2}$ University of Queensland, Queensland Brain Institute, Brisbane, Australia

Corresponding author:

Andrew K. Martin

e: a.martin11@uq.edu.au

\section{Copyright}

The copyright holder for this preprint is the author/funder. It is made available under a CCBY-NC-ND 4.0 International license.

Draft version 1.0, 02.04.2018; This paper has not been peer-reviewed. 


\begin{abstract}
Background: Advanced age is associated with difficulties in understanding the emotional or mental state of others. However, little is known about the underlying cognitive processes that may contribute. We investigate how perspective taking changes in older adults and how this relates to executive and social cognition.
\end{abstract}

Method: Using a novel visual perspective taking (VPT) task, 50 healthy older adults and 122 healthy young adults completed measures of implicit VPT (i.e. egocentric-perspective only) and level one (i.e number of balls seen from egocentric/allocentric) and two (i.e. more balls on left or right from egocentric/allocentric) explicit VPT. Age differences on accuracy and response time (RT) were analysed. Baseline executive and social cognitive functioning were assessed for processing speed, updating, response inhibition, set-switching, affective theory of mind (ToM), and social-emotional cognition. Regression models were used to determine the relationship between VPT, executive, social cognition and ageing.

Results: Older adults were slower when required to switch to the allocentric perspective in both level one and two VPT tasks. Congruency effects (impaired performance when scenes were incongruent with the alternate perspective) were identified for accuracy and RT for the egocentric and allocentric conditions of both level one and two explicit VPT. Older adults also displayed a greater congruency effect during the egocentric trials of the level two VPT task. Younger adults displayed a greater congruency effect for errors on the egocentric condition of the level one VPT task. Congruency effect for errors on the allocentric condition of both level one and two VPT tasks correlated with social emotional cognition, such that a greater ability to inhibit the egocentric perspective was associated with better social cognitive performance. Switching to the allocentric perspective was associated with both processing speed and response inhibition and these partially, but not completely, explained the agerelated effects on switch cost. A robust implicit VPT effect was identified in both young and older adults.

Conclusion: Social difficulties may arise in older adults due to difficulty switching to the allocentric perspective. A greater tendency to rotate into allocentric perspectives during egocentric judgements may reflect a weaker embodied self in older adults. Executive and social cognition are associated with perspective taking ability, but these only partially explain age-related performance differences. Lower level perspective taking difficulty should be considered in studies of social difficulties in advanced age. 
Visual Perspective Taking

\section{Introduction}

Social interaction requires understanding alternate perspectives. Specifically, understanding what another person knows, sees, or believes requires taking another's perspective and distinguishing it from one's own. Older adults have increased difficulty with higher-order social tasks such as mental state attribution (Henry, Phillips, Ruffman, \& Bailey, 2013) which has an effect on interpersonal functioning (Bailey, Henry, \& Von Hippel, 2008). However, little is known about the underlying cognitive processes, such as perspective taking, that may contribute to social understanding.

Visual perspective taking (VPT) refers to the ability to understand a visual scene both from the viewpoint of the self (egocentric) and from another location (allocentric). This is a highly adaptive feature of human cognition (Tomasello, 1999) and thought to underpin higher-order social cognitive functions such as theory of mind (ToM; i.e. the ability to take on the mental perspective of others and distinguish from one's own; Hamilton, Brindley, \& Frith, 2009). Both implicit and explicit levels of VPT have been proposed (Apperly \& Butterfill, 2009). Implicit perspective taking refers to the subconscious, automatic representation of other agents' perspectives. This can be observed in tasks that require the subject to answer only from the egocentric perspective. An implicit VPT effect refers to response slowing when one perceives a scene that is incongruent with the perspective of another person. This effect is not observed in scenes with an inanimate object, and supports the theoretical claim of dual-processes for implicit and explicit social cognition (Apperly \& Butterfill, 2009; Frith \& Frith, 2008; Kovacs, Teglas, \& Endress, 2010; Uleman, 1999). Explicit perspective-taking refers to tasks that direct the subject to attend and/or switch between both self and other perspectives. When taking the other perspective, the subject may be asked "if" an object can be seen. These tasks are often referred to as "level one" VPT, as they can be answered using line-of-sight judgements from the position of the subject. When the subjects are required to answer "how" an object is seen from the other person's perspective, it is thought to induce a mental rotation into the perspective of the other in order to answer correctly. Tasks that require this rotation are often labelled "level two" VPT. The simplest version of a level two task is to ask a laterality question from the other perspective (Kessler \& Rutherford, 2010; Michelon \& Zacks, 2006), for example, "Does the other person see more items on their left or right?" In order to answer 
such questions. Subjects must mentally rotate the self-perspective into the alternate location, often termed an embodied rotation (Kessler \& Rutherford, 2010; Pearson, Ropar, \& Hamilton, 2013; Wang, Callaghan, Gooding-Williams, McAllister, \& Kessler, 2015).

Previous research has shown that older adults' perception becomes increasingly egocentric and favours self-relevant aspects of cognitive tasks (Hess, 2014; Riva, Triscoli, Lamm, Carnaghi, \& Silani, 2016). To date, only one study has investigated age-effects in a VPT task. Mattan et al (2017) found that older adults favoured the self-perspective in a task that required subjects to judge whether a scene matched the prompted number of dots when the scene was either congruent or incongruent with the perspective of another avatar. The authors argue that older adults showed impairments at the perspective-selection phase, hampering their ability to flexibly change between self and alternate perspectives. As the selfperspective is the "default" (Surtees \& Apperly, 2012), taking the alternative perspective requires more computational steps, resulting in difficulty specifically for alternative perspective judgements. The results of the Mattan et al (2017) study are limited to explicit level one VPT. No studies, to date, have investigated implicit VPT or level two VPT in older adults.

Importantly, perspective taking requires the calculation of both self and other perspective and then selection of the appropriate perspective for the demands of the task (Ramsey, Hansen, Apperly, \& Samson, 2013; Samson, Apperly, Braithwaite, Andrews, \& Bodley Scott, 2010). It has been argued that although perspective calculation happens implicitly, without demands on other cognitive processes (Apperly \& Butterfill, 2009; Samson et al., 2010; Surtees \& Apperly, 2012; although see Conway, Lee, Ojaghi, Catmur, \& Bird, 2017; Santiesteban, Catmur, Hopkins, Bird, \& Heyes, 2014), perspective-selection is thought to engage executive processes (Qureshi, Apperly, \& Samson, 2010; Ramsey et al., 2013). For example, Qureshi et al, (2010) demonstrated that when participants were required to concurrently perform an executive task (incongruent finger-tapping to an auditory prompt), response times were slower when scenes were incongruent from either the egocentric or allocentric (other's) perspective, suggesting a cognitive cost of perspective-selection. On the contrary, they found no effect on perspective calculation, as the concurrent executive task increased rather than decreased the effect of the incongruent allocentric perspective during 
egocentric judgements. In other words, performing an executive task did not prevent the subjects from calculating the alternative perspective, even when it was not required for the current task demands. As executive functions are frequently impaired in advanced age (Albinet, Boucard, Bouquet, \& Audiffren, 2012; Borella, Carretti, \& De Beni, 2008; Bugg, DeLosh, Davalos, \& Davis, 2007; Salthouse, 2012), older adults should show a greater perspective selection difficulty across both level one and two VPT tasks, during both egocentric and allocentric perspective judgements. Moreover, a correlation should be identified between perspective selection and other executive tasks that recruit similar frontoparietal networks (Ramsey et al., 2013).

Level two VPT refers the ability to judge how something is seen from an alternative perspective. Although there are many ways in which level two VPT tasks have been defined (Hamilton et al., 2009), a simple method is to ask participants to make a laterality judgement (Michelon \& Zacks, 2006). Laterality judgements are thought to induce a more embodied mental rotation into the alternative perspective (Surtees, Apperly, \& Samson, 2013), whereby the subject actively imagines themselves in the alternate location rather than use other strategies such as "line-of-sight" calculations from the egocentric viewpoint. Developmentally, level two VPT ability matures around the age of four (Gzesh \& Surber, 1985), similar to ToM and executive abilities (Carlson \& Moses, 2001) and is thought to place greater demand on cognitive resources (Apperly \& Butterfill, 2009). Therefore, if level two VPT relies on greater executive resources, older adults should show greater impairment. Likewise, the correlation between executive tasks and level two VPT measures should be greater across both young and older adults. It has also been proposed that older adults are less embodied in their cognitive style (Costello \& Bloesch, 2017). For example, compared to young adults, older adults retain the ability to rotate objects, but show impairments when asked to rotate images of the human body (Devlin \& Wilson, 2010). If this is the case, older adults may have difficulty switching to the alternative perspective during level two VPT, but a weaker body schema may result in rotation when rotation is not required as indexed by a greater intrusion of the non-relevant alternative perspective during egocentric judgements.

Several studies into VPT have used a version of the Dot Task (Apperly \& Butterfill, 2009). In this task subjects are required to answer whether the number of dots seen is consistent with 
the number of dots seen by an avatar in the scene. Using this task, it has been demonstrated that adults automatically calculate the perspective of other people but not non-social stimuli (Apperly \& Butterfill, 2009; Ferguson, Apperly, \& Cane, 2017; Qureshi et al., 2010; Samson et al., 2010). However, an alternative view has been put forward stating that rather than automatically calculating the perspective of others, the eye gaze of the avatar results in an "attention grab" to the left or right of the scene and thus explains the slower response times for inconsistent scenes which is equally achievable using directional cues such as arrows (Santiesteban et al., 2014). In the current study we introduce a novel measure of visual perspective taking able to investigate implicit and explicit processes without the confound of directing gaze laterally.

In sum, we investigated VPT across three levels in young and older adults and explored the relationship with both executive and social cognition. The study specifically addressed the following research questions: (1) Are older adults impaired on measures of VPT compared to younger adults? (2) To what extent are VPT measures correlated with executive and social cognition and can these explain age-related effects? (3) Can we identify an implicit VPT effect, is it similar in young and older adults, and is it robust to task expectations?

We hypothesized that older adults would be slower and produce a greater number of errors when switching to the allocentric perspective for both level one and two explicit visual perspective taking tasks. Older adults would show a greater congruency effect than younger adults during both egocentric and allocentric perspective conditions for both level one and two VPT, with a greater difference identified in level two. Performance on executive measures would partially explain age-related differences on all VPT measures. An Implicit VPT would be identified that is robust to task expectations, would not be associated with executive functioning and would remain intact in older adults. 
Visual Perspective Taking

\section{Method}

\subsection{Participants}

A total sample of 172 adults, including 50 older (55-80yrs) and 122 young (18-36yrs) were recruited from The University of Queensland and the surrounding Brisbane metropolitan area. All participants reported no history of neurological or psychiatric illness and had no history of substance abuse. Young and Older adults were comparable for autism related traits as measured by the Autism Spectrum Quotient (ASQ; Baron-Cohen, Wheelwright et al, 2001; see Table 1.).

All data presented were acquired in studies that investigated the effects of transcranial direct current stimulation (tDCS) on social cognition in a counter-balanced, cross-over, placebo stimulation controlled design (Martin, Dzafic, Ramdave, \& Meinzer, 2017; Martin, Huang, Hunold, \& Meinzer, 2017). Only data from the placebo-stimulation condition are reported here. However, due to the cross-over design (i.e., $50 \%$ of the participants received placebo stimulation during either session one or two), the robustness of the implicit VPT effect to task expectations was able to be assessed using the novel VPT task. This is because in session one, subjects are unaware of upcoming demands on switching between self and other perspectives and should not attend to stimuli in the scenes other than those required for the egocentric perspective. Therefore, if the implicit VPT effect is only apparent in session two, it would suggest that the effect is due to task expectations rather than an implicit effect. Importantly, session order had no effect on any congruency measures. Although allocentric switch times were faster in session two, session order had no interaction with any Age Group effects presented. Therefore, we present data collapsed across both sessions.

\subsection{Visual perspective taking (VPT) task}

The VPT task (Martin, Dzafic, et al., 2017) involved three separate tests measuring level one VPT (implicit and explicit) and level two VPT (explicit). All tests involved a street scene with tennis balls, rubbish bins, and either a human avatar or a traffic light directly in front of the gaze of the subject at one of three positions on the street - far, middle, or near (see Figure 1). 
The traffic light was used as a directional control that should direct attention in a similar manner to the human avatar, but crucially without the ability to hold a perspective of the scene, which was particularly of interest in the implicit VPT task (Apperly \& Butterfill, 2009; Samson et al., 2010). The test consisted of 176 trials. In $50 \%$ of the trials ( $n=88$ ) a human avatar was present and in $50 \%$ of the trials a traffic light was present. The trials were further separated ( $50 \%$ each, resulting in 44 trials in each condition) by whether the number of balls seen by the subject was congruent or incongruent with that of the human avatar's view or the number of tennis balls the light would directly hit. This resulted in four conditions; avatar congruent, avatar incongruent, light congruent, light incongruent (see Figure 1). All conditions were balanced for number and location of tennis balls and each condition could not appear more than twice in a row. Each VPT had four counterbalanced versions. All tests were completed in the following order: level one implicit, level one explicit, and level two explicit. Subjects were instructed to answer as quickly and as accurately as possible. The stimuli remained on the screen until a response was recorded. A fixation cross was presented for 500ms prior to the stimuli. For the level one and level two VPT, the word "you" or "other" was presented for $750 \mathrm{~ms}$ prior to the presentation of the scene. Subjects were informed that tennis balls would be hidden from the avatar's view if a rubbish bin occluded the view or if the tennis ball was behind the avatar. If the traffic light was present, the subjects were instructed to imagine the light radiating out from the traffic light towards the subject and to answer how many tennis balls the light would directly hit. Again, if a bin occluded the light or if the ball was behind the traffic light, the light would not directly hit the ball. Subjects completed six practice trials for the implicit and twenty-four practice trials for both explicit VPT tasks.

\subsection{Baseline cognitive measures}

Executive tasks were selected in line with recommendations from Miyake et al (2000) to include measures of updating (2-back accuracy), response inhibition (Stroop Effect), and switching (Set-switching from CogState, www.cogstate.com). We also included the 1-back response time due to the relationship between processing speed with age-related declines in executive abilities (Salthouse, 1996). We also chose the 1-back RT as the explicit VPT tasks 
require holding the "you" or "other" cue in working memory in a similar manner as a 1-back task.

A)

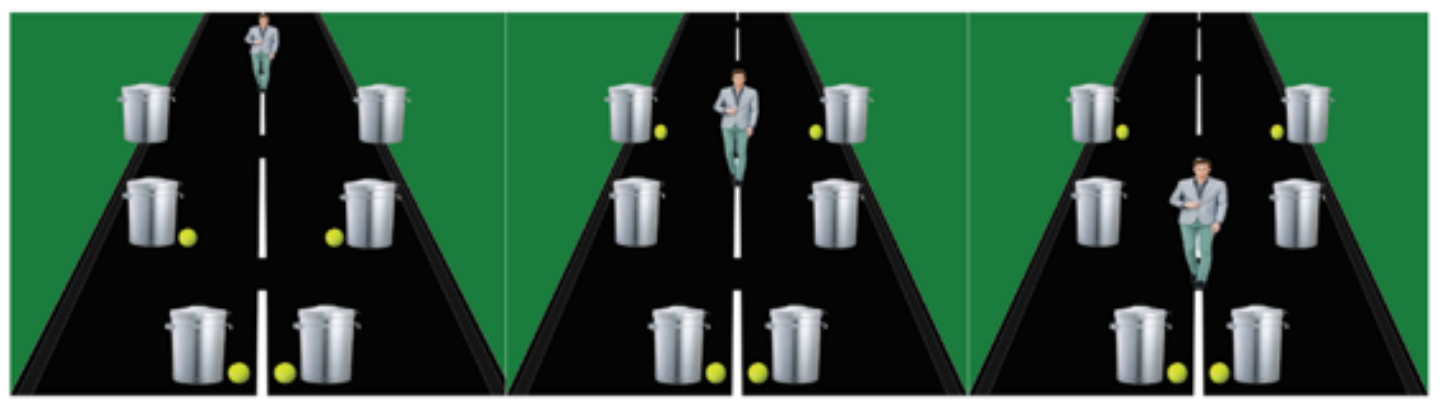

B)

C)

AVATAR

TRAFFIC LIGHT
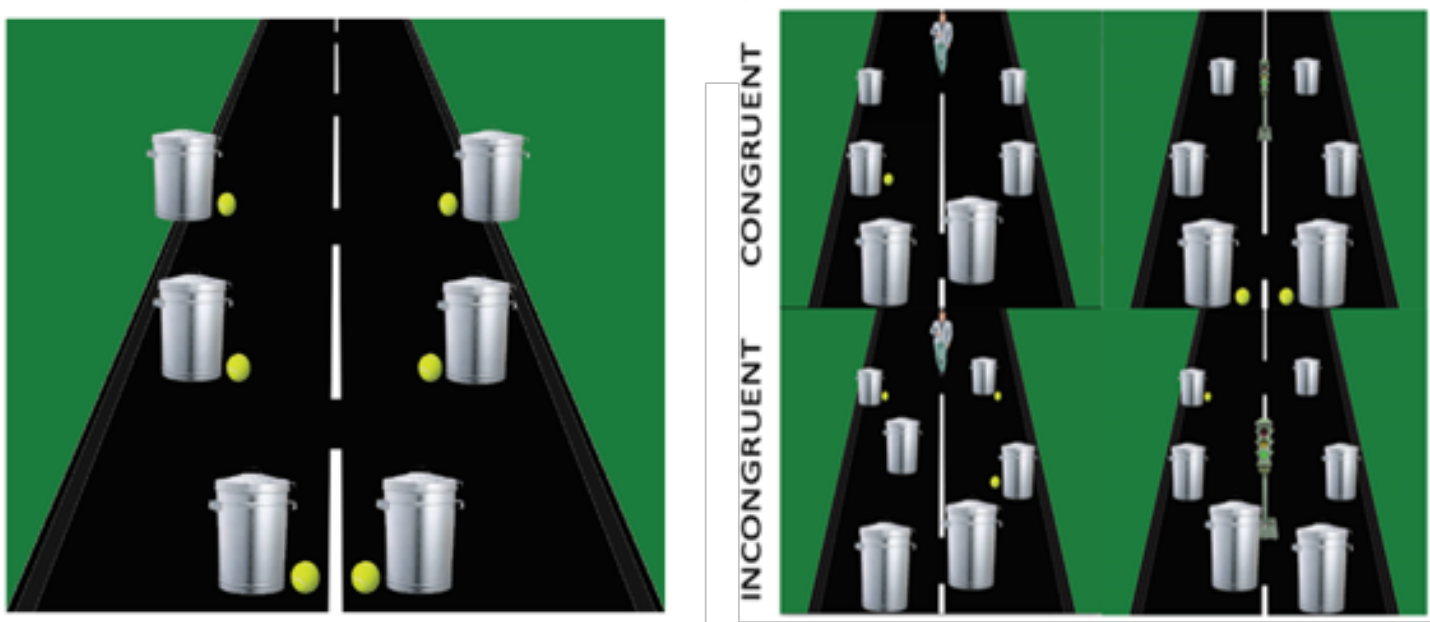

Figure 1. The Visual Perspective Taking (VPT) Task. A) The three possible locations of the avatar (or traffic light). B) The six possible locations of the tennis balls. One to four balls were presented in any of the six locations. C). Examples of congruent and incongruent conditions for both the avatar and the traffic light.

\subsubsection{1-back working memory speed}

Subjects were presented with a playing card in the middle of the screen and asked if the previous card was the same. Processing speed was calculating using a log transformation of the response times.

\subsubsection{2-back working memory accuracy}

Subjects were presented with a playing card in the middle of the screen and asked if the previous card was the same as the card shown two cards previous. Accuracy was calculated using arcsine square root of the proportion of correct responses. 


\subsubsection{Set-switching task}

A playing card is presented in the middle of the screen. At the start of the task, the subject guesses whether the card is the "target" card. The next stimuli is not presented until the subject guesses correctly. When the subject has made their way through a set of cards, the "target" stimulus changes, either from red to black (intra-dimensional shift) or from colour to number (extra-dimensional shift). The subject is not told when these shifts will occur, and they must relearn the new target rule to proceed through the task. Number of errors was calculated and used as a measure of set-switching ability.

\subsubsection{Stroop test}

Participants initially read out a list of coloured blocks followed by a list of words for colours. In the inhibition condition words were printed in incongruent ink colour and subjects were instructed to ignore the word and read out the colour of the ink that the word was printed. A Stroop Effect was calculated by finding the ratio of time taken for the incongruent colourword to the word only condition.

\subsubsection{Social-emotional cognition task (SEC)}

The subject is presented with four pictures of faces displaying emotion or gaze direction and are instructed to pick the odd one out. Accuracy was calculated and used as a measure of social cognitive ability.

\subsubsection{Reading the mind in the eyes (Baron-Cohen, Wheelwright, Hill, Raste, \& Plumb, 2001)} The subject was presented with a picture of the eye region of a human face with four options regarding the emotional or cognitive state best represented within the eyes. Subjects were instructed to select the best option. Total out of 38 was calculated and used as a measure of affective theory of mind (ToM).

\subsection{Statistical analyses}

Individual responses were removed if they were greater than three standard deviations from the mean. At the group level, any univariate outlier ( $>3$ SD from mean) was removed and the 
analysis rerun. If the outlier did not alter the interpretation, then the initial analysis with complete data was retained.

Subjects were excluded from the specific VPT task if they scored $50 \%$ correct or less on any condition within the task or if overall response times were greater than 3 standard deviations from the mean. This resulted in the removal of 11 young and 6 older adults for the VPT level one, and 11 young and 9 older for VPT level two. Therefore, the total sample was 122/50 for implicit VPT, 115/46 for level one VPT, and 112/43 for level two VPT. For the correlation analyses, six subjects (4 young, 2 older) included in the implicit VPT, four subjects included in VPT level one ( 3 young, 1 older), three included in VPT level two ( 2 young, 1 older) did not have CogState data (Set-switching \& Social-Emotional Cognition Tasks). One young subject included in all VPT analyses did not complete the Stroop Test.

JASP version 0.8.3.1 was used for all analyses. To quantify evidence for age group differences and association with other cognitive measures, we analyzed our data using Bayes Factors (BF). A BF quantifies the evidence for a particular statistical model (the null $\mathrm{H}_{0}$ and the alternate $\mathrm{H}_{1}$ ). For example, a BF of 12 equates to the data being 12 times as likely from one model compared to the alternate model. All analyses used default priors in JASP 0.8.3.1 as recommended (Wagenmakers, Marsman, et al., 2017; Wetzels \& Wagenmakers, 2012). Strength of evidence was as follows: $\mathrm{BF}_{10}$ 1-3 anecdotal evidence for alternate model, 3-10 moderate, 10-30 strong, 30-100 very strong, $>100$ extreme evidence. $\mathrm{BF}_{10}<1$ provides evidence for the null model with strength of evidence represented in an inverse fashion, $\mathrm{BF}_{10}$ 0.3-1 anecdotal, 0.1-0.3 moderate, <0.1 strong (Wagenmakers, Love, et al., 2017). Support for the null as well as the alternate hypothesis is a strength of the Bayesian approach and also removes issues concerning multiple comparisons (Gelman, Hill, \& Yajima, 2012). Anecdotal evidence should be treated with caution until future replication strengthens the evidence in the direction of the null or alternate hypothesis.

For repeated measures analysis of variance (RM-ANOVA) and linear regression analyses, the main effect for each covariate and Age Group and their interaction terms were assessed using $\mathrm{BF}$ inclusion ( $\mathrm{BF}$ inc). $\mathrm{A} \mathrm{BF}_{\text {inc }}$ is synonymous with $\mathrm{BF}_{10}$ and provides support for the inclusion of the main effect or interaction term in the linear regression model. $A B_{\text {inc }}>1$ provides support 
for the inclusion of the effect in the regression model. Strength of evidence is identical to the $\mathrm{BF}_{10}$ explained above.

For correlation analyses, a $\mathrm{BF}_{10}$ provides evidence for the absence or presence of an effect in an identical manner to that mentioned above. A posterior distribution is provided in all figures that quantifies the uncertainty about the size of the effect under the assumption that it exists (Wagenmakers, Love, et al., 2017; Wagenmakers, Marsman, et al., 2017). A median and 95\% credible interval is provided.

\section{Results}

Demographic and baseline cognitive performance in young and older adults is presented in Table 1. Descriptive statistics for all VPT measures are provided in Table 2. No outliers affected the interpretation of the data and so results represent the complete data for all measures.

Table 1: Demographic and baseline cognitive performance for young and older adults.

\begin{tabular}{lcccc}
\hline & $\mathrm{N}$ & Young Adults & Older Adults & $\mathrm{BF}_{10}$ \\
\hline Age (years) & & $23.83(3.80)$ & $66.18(5.97)$ & - \\
& & $\begin{array}{c}\text { range } 18-36 \\
\text { range } 55-80\end{array}$ & \\
Sex & $63 \mathrm{~F} / 59 \mathrm{M}$ & $28 \mathrm{~F} / 22 \mathrm{M}$ & 0.24 \\
ASQ & $122 / 50$ & $15.47(5.82)$ & $14.98(6.25)$ & 0.20 \\
1-back RT & $120 / 48$ & $2.86(0.09)$ & $2.92(0.09)$ & 121.50 \\
2-back Acc & $120 / 48$ & $1.27(0.15)$ & $1.20(0.13)$ & 14.49 \\
Set-Switching & $118 / 48$ & $16.52(8.45)$ & $14.75(6.00)$ & 0.41 \\
Stroop Effect & $120 / 48$ & $22.53(9.17)$ & $29.57(11.43)$ & 504.46 \\
RMET & $122 / 50$ & $27.06(3.58)$ & $26.82(3.84)$ & 0.19 \\
Soc-Emo Cognition & $120 / 48$ & $1.14(0.13)$ & $1.11(0.11)$ & 0.48 \\
\hline
\end{tabular}


Visual Perspective Taking

Table 2. Performance on the visual perspective taking task for young and older adults.

\begin{tabular}{|c|c|c|}
\hline & Young Adults & Older Adults \\
\hline Implicit VPT & $\mathrm{N}=122$ & $\mathrm{~N}=50$ \\
\hline Avatar CE RT (msecs) & $12.67(21.89)$ & $11.15(32.67)$ \\
\hline Light CE RT (msecs) & $-5.00(20.70)$ & $-6.33(31.27)$ \\
\hline Avatar CE Acc & 0.07 (1.70) & $-0.35(1.45)$ \\
\hline Light CE Acc & $-0.22(1.63)$ & $-0.25(1.22)$ \\
\hline Explicit level 1 VPT & $\mathrm{N}=115$ & $N=46$ \\
\hline Egocentric CE RT total & $128.37(126.91)$ & $139.99(113.46)$ \\
\hline Avatar & $120.11(169.22)$ & $128.60(162.52)$ \\
\hline Light & $136.64(138.28)$ & $151.39(177.62)$ \\
\hline Egocentric CE Acc total & $1.52(1.72)$ & $0.80(1.07)$ \\
\hline Avatar & $1.57(2.07)$ & $0.89(1.35)$ \\
\hline Light & $1.46(1.82)$ & $0.72(1.36)$ \\
\hline Allocentric CE RT total & $193.40(144.32)$ & $150.14(138.55)$ \\
\hline Avatar & $225.10(181.03)$ & $218.96(194.11)$ \\
\hline Light & $161.70(184.01)$ & $91.31(179.84)$ \\
\hline Allocentric CE Acc total & $1.12(1.53)$ & $1.01(1.51)$ \\
\hline Avatar & $1.33(1.86)$ & $1.07(1.53)$ \\
\hline Light & $0.91(1.90)$ & $0.96(2.07)$ \\
\hline Switch cost RT & $367.73(186.53)$ & $756.34(215.66)$ \\
\hline Switch cost Acc & $0.12(1.26)$ & $0.46(0.98)$ \\
\hline Explicit level 2 VPT & $\mathrm{N}=112$ & $N=43$ \\
\hline Egocentric CE RT total & $150.80(172.96)$ & $273.13(252.45)$ \\
\hline Avatar & $128.55(211.28)$ & 259.58 (319.99) \\
\hline Light & $173.06(224.36)$ & $286.69(295.67)$ \\
\hline Egocentric CE Acc total & $0.47(1.16)$ & $0.62(1.34)$ \\
\hline Avatar & $0.01(1.60)$ & $0.35(1.67)$ \\
\hline Light & $0.95(1.55)$ & $0.88(1.50)$ \\
\hline Allocentric CE RT total & 229.51 (186.95) & $212.65(254.15)$ \\
\hline Avatar & $216.93(245.31)$ & 209.38 (332.39) \\
\hline Light & $242.08(239.94)$ & $215.92(354.17)$ \\
\hline Allocentric CE Acc total & $0.91(1.34)$ & $1.24(1.35)$ \\
\hline Avatar & $0.96(1.79)$ & $1.30(1.47)$ \\
\hline Light & $0.85(1.73)$ & $1.19(1.97)$ \\
\hline Switch cost RT & $495.00(305.62)$ & $942.79(370.88)$ \\
\hline Switch cost Acc & $0.56(1.33)$ & $0.81(1.31)$ \\
\hline
\end{tabular}

$\mathrm{CE}=$ Congruency Effect; $\mathrm{RT}=$ Response time; Acc= Accuracy; All RTs are msecs 
Visual Perspective Taking

\section{1 Explicit visual perspective taking}

3.1.1 VPT level one

\subsubsection{Switching from egocentric to allocentric perspective}

For response time, older adults had a greater allocentric switch cost than younger adults, $\mathrm{BF}_{10}$ $=1.373 e+19$. For accuracy, no Age Group difference was identified, $B F_{10}=0.630$. (see Figure 2).
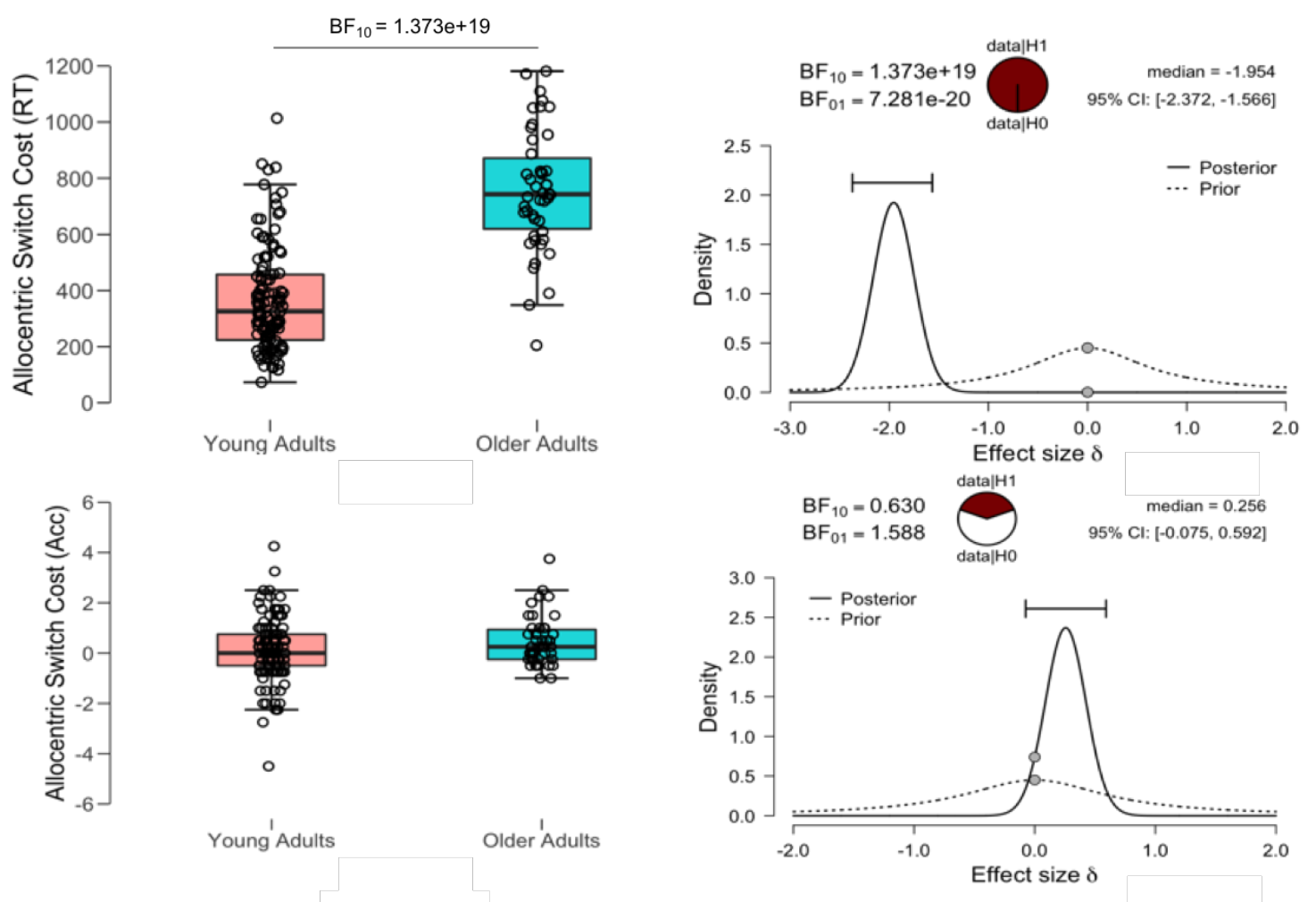

Figure 2. Level 1 Visual Perspective Taking switch costs. Allocentric switch cost refers to the response time and accuracy difference between egocentric and allocentric conditions. Extreme evidence was found for a greater cost of switching to the allocentric perspective for both level 1 and 2 visual perspective taking in older adults. Prior and posterior distributions, the median effect size and a $95 \%$ credible interval are provided. The pie charts provide a visual representation of the evidence for the null or alternate model. 


\subsubsection{Egocentric congruency effects}

For response time, a congruency effect was demonstrated, $\mathrm{BF}_{\text {inc }}=1.073 \mathrm{e}+38$, such that response times were greater for incongruent scenes. No Agent x Congruency interaction was found, $B F_{i n c}=0.214$. An Age Group effect was identified, $B F_{i n c}=5.016 e+8$ such that response times were greater for older adults. No Age Group x Congruency interaction was shown, $\mathrm{BF}_{\text {inc }}$ $=0.155$ nor was an Age Group x Congruency x Agent interaction, $\mathrm{BF}_{\text {inc }}=0.213$ (see Figure 3).

For accuracy, a congruency effect was identified, BFinc $=4.142 \mathrm{e}+35$ such that incongruent scenes produced more errors. An Age Group effect was found, $\mathrm{BF}_{\mathrm{inc}}=44.614$ such that older adults were more accurate. An Age Group x Congruency interaction was demonstrated, $\mathrm{BF}_{\text {inc }}$ $=60.724$ such that older adults were more accurate on incongruent trials. No Agent $x$ Congruency interaction, $\mathrm{BF}_{\mathrm{inc}}=0.106$ nor Age Group $\times$ Agent $\times$ Congruency interaction, $\mathrm{BF}_{\mathrm{inc}}=$ 0.202, was identified (see Figure 3).
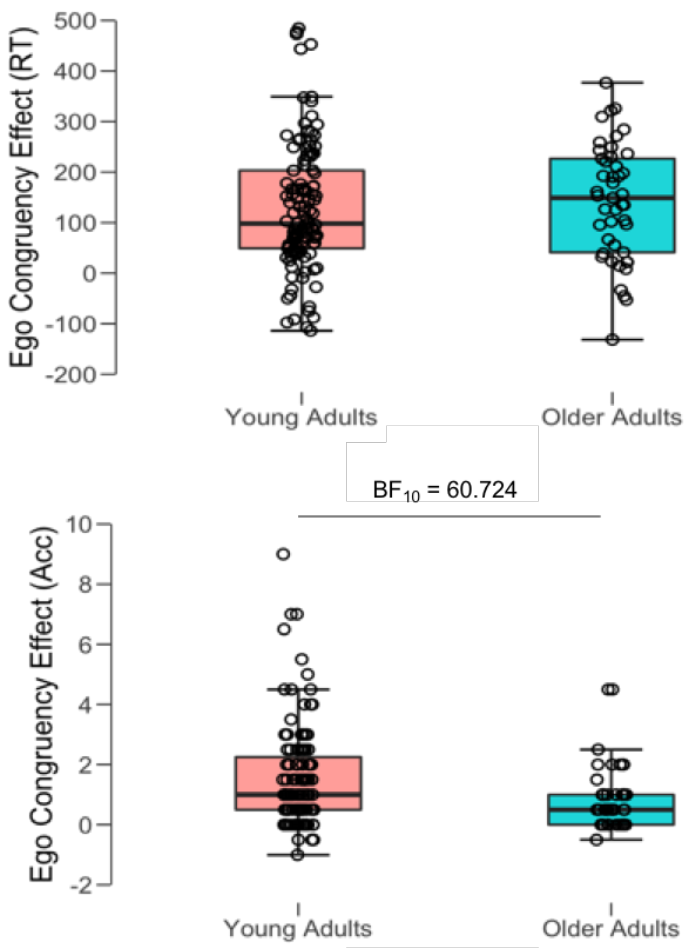

$\mathrm{BF}_{10}=60.72$

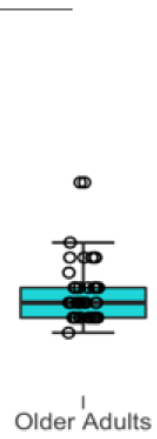

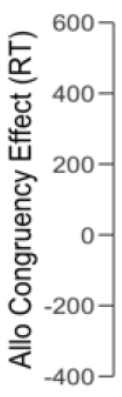
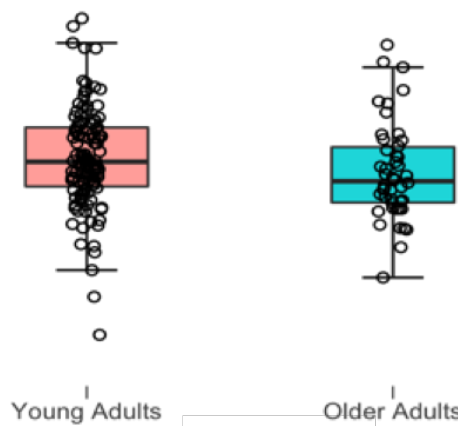

Older 'Adults
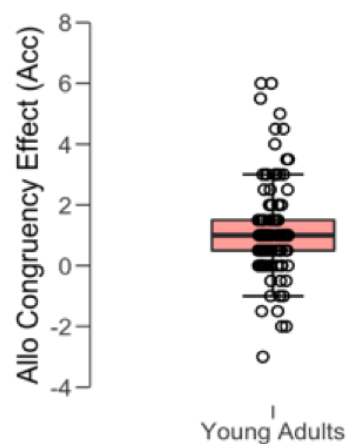

$\circ$

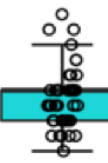

Older 'Adults

Figure 3. Level 1 visual perspective taking. Congruency effect refers to the difference between congruent and incongruent trials and is calculated for both response time and accuracy. Strong evidence was demonstrated for a greater intrusion of the allocentric perspective into the egocentric perspective for young adults, as indexed by greater congruency effect on accuracy during egocentric trials. 
Visual Perspective Taking

\subsubsection{Allocentric congruency effects}

For response time, a congruency effect was found, $\mathrm{BF}_{\mathrm{inc}}=1.827 \mathrm{e}+48$, such that response times were greater for incongruent scenes. An Agent x Congruency interaction was identified, $\mathrm{BF}_{\mathrm{inc}}=170.526$ such that the congruency effect was greater when taking the perspective of the avatar (214msecs) compared to the light (142msecs). An Age Group effect was demonstrated, $\mathrm{BF}_{\text {inc }}=1.497 \mathrm{e}+19$ such that response times were greater for older adults. No Age Group $x$ Congruency, $\mathrm{BF}_{\text {inc }}=0.622$, nor Age Group $\times$ Agent $\times$ Congruency, $\mathrm{BF}_{\text {inc }}=0.492$ interactions were identified (see Figure 3).

For accuracy, a congruency effect was apparent, $\mathrm{BF}_{\mathrm{inc}}=3.090 \mathrm{e}+21$ with incongruent scenes producing more errors. No Agent $x$ Congruency Effect was identified, $\mathrm{BF}_{\mathrm{inc}}=0.463$. There was no effect of Age Group, $\mathrm{BF}_{\text {inc }}=0.349$ and no Age Group $x$ Congruency, $B F_{\text {inc }}=0.163$ nor Age Group x Agent $x$ Congruency, $\mathrm{BF}_{\mathrm{inc}}=\mathbf{0 . 2 1 1}$, interactions (see Figure 3).

\subsubsection{VPT level two}

\subsubsection{Switching from egocentric to allocentric perspective}

For response time, older adults had a greater allocentric switch cost than younger adults, $\mathrm{BF}_{10}$ $=3.566 \mathrm{e}+9$. For accuracy, no Age Group difference was found, $B F_{10}=0.318$. (see Figure 4) 

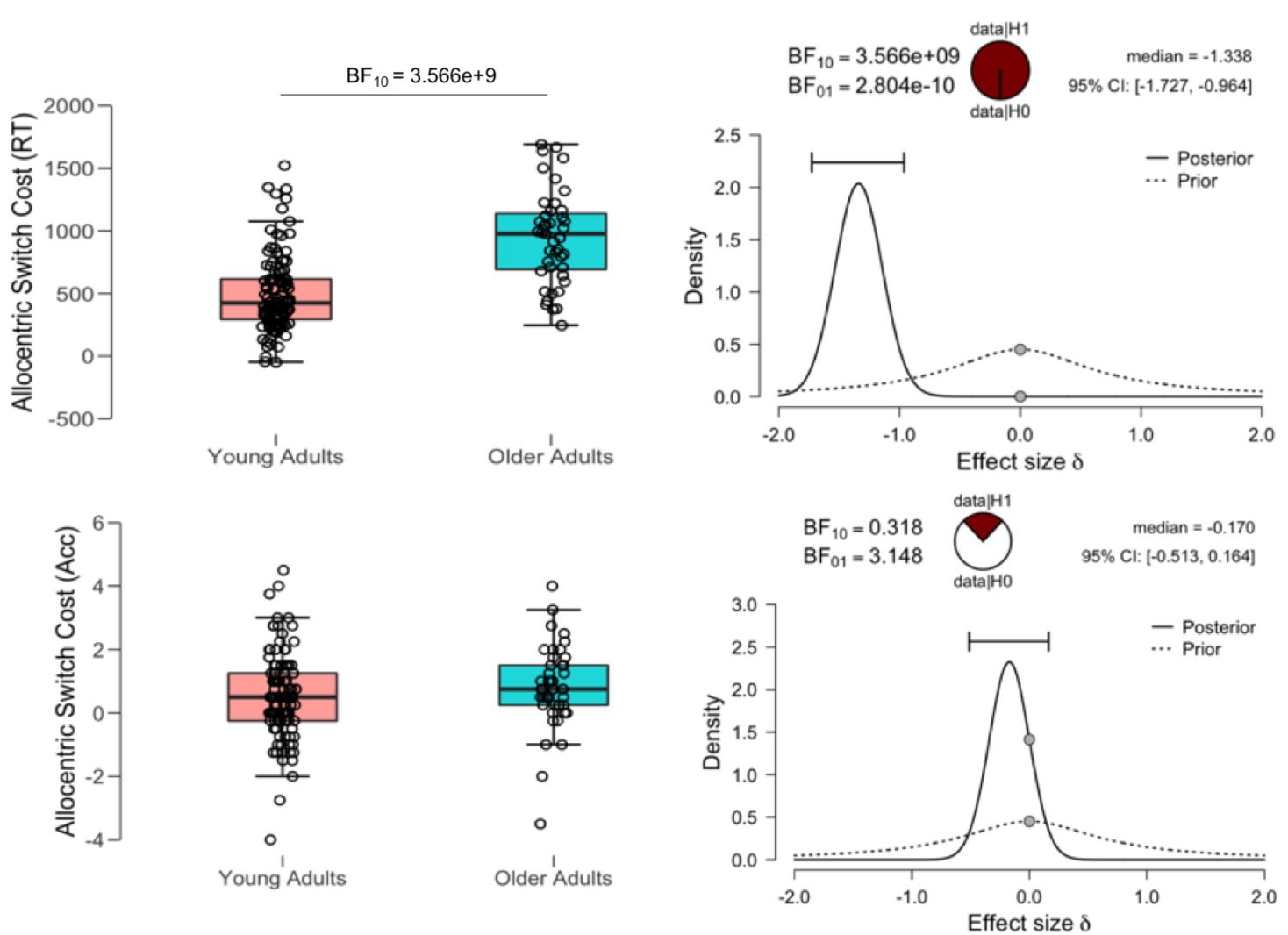

Figure 4. Level 2 Visual Perspective Taking switch costs. Allocentric switch cost refers to the response time and accuracy difference between egocentric and allocentric conditions. Extreme evidence was found for a greater cost of switching to the allocentric perspective for both level 1 and 2 visual perspective taking in older adults. Prior and posterior distributions, the median effect size and a $95 \%$ credible interval are provided. The pie charts provide a visual representation of the evidence for the null or alternate model

\subsubsection{Egocentric congruency effect}

For response times, a congruency effect was identified, $B F_{i n c}=6.764 \mathrm{e}+30$ revealing that response times were greater for incongruent scenes. No Agent $x$ Congruency effect was found, $B F_{i n c}=0.306$. An Age Group effect was demonstrated, $B F_{i n c}=2.375 e+14$ such that older adults response times were greater. An Age Group x Congruency interaction was identified, $B F_{i n c}=219.995$, such that the congruency effect was greater in older adults. No Age Group $x$ Agent $x$ Congruency interaction was identified, $\mathrm{BF}_{\text {inc }}=0.266$ (see Figure 5).

For accuracy, a congruency effect was demonstrated, $\mathrm{BF}_{\mathrm{inc}}=343623.440$, whereby incongruent scenes produced more errors. An Agent $x$ Congruency effect was identified, $\mathrm{BF}_{\text {inc }}$ $=5341.151$, such that the congruency effect is greater when a traffic light was present in the 
Visual Perspective Taking

scene compared to the avatar. There was no effect of Age Group, $B F_{\text {inc }}=0.202$ and no Age Group $x$ Congruency, $\mathrm{BF}_{\text {inc }}=0.185$ nor Age Group $\mathrm{x}$ Agent $\mathrm{x}$ Congruency, $\mathrm{BF}_{\mathrm{inc}}=0.330$ interactions (see Figure 5).

\subsubsection{Allocentric congruency effect}

For response times, a congruency effect was identified, $B F_{i n c}=2.285 e+36$ revealing that response times were greater for incongruent scenes. No Agent x Congruency interaction was identified, $\mathrm{BF}_{\mathrm{inc}}=0.152$. An Age Group Effect was identified, $\mathrm{BF}_{\mathrm{inc}}=1.185 \mathrm{e}+16$ such that older adults response times were greater. No Age Group $x$ Congruency, $\mathrm{BF}_{\mathrm{inc}}=0.154$ nor Age Group $x$ Agent $x$ Congruency, $\mathrm{BF}_{\text {inc }}=0.223$ interactions were identified (see Figure 5).

For accuracy, a congruency effect was apparent, $\mathrm{BF}_{\mathrm{inc}}=1.637 \mathrm{e}+20$ with incongruent scenes resulting in more errors. No Agent $x$ Congruency interaction was identified, $\mathrm{BF}_{\text {inc }}=0.151$. There was no effect of Age Group, $\mathrm{BF}_{\mathrm{inc}}=0.250$ and no Age Group $\times$ Congruency, $\mathrm{BF}_{\text {inc }}=0.421$ nor Age Group x Agent $x$ Congruency, $\mathrm{BF}_{\mathrm{inc}}=0.187$ interactions (see Figure 5). 

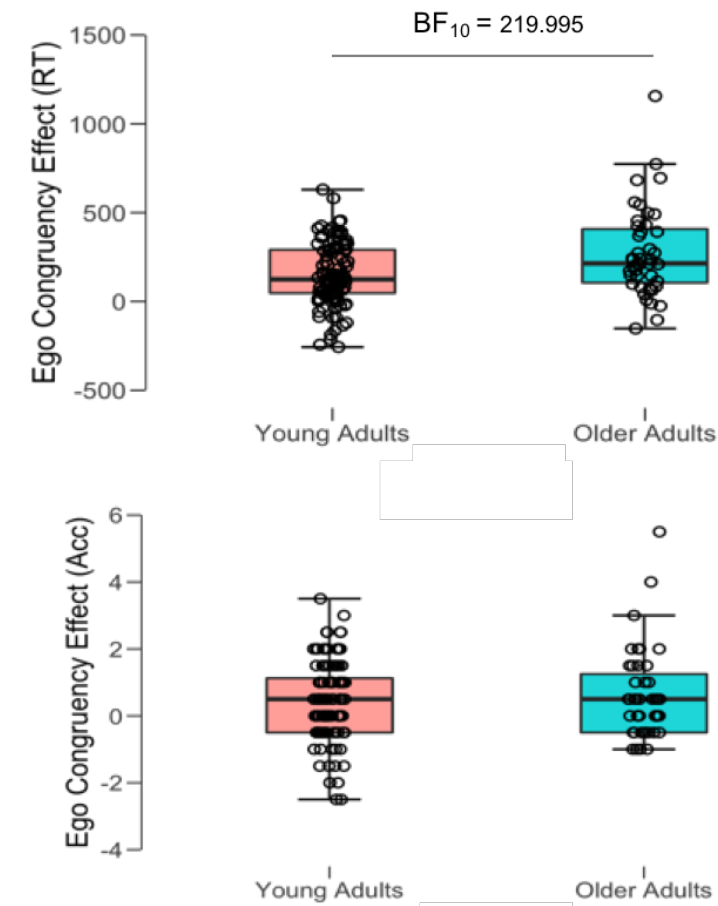
Older Adults
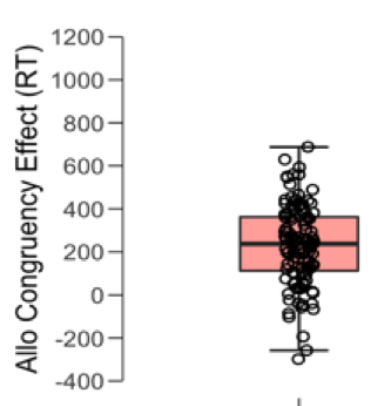

Young Adults

Older Adults

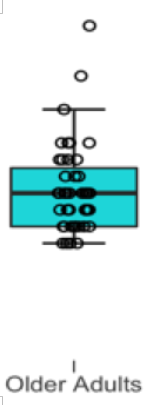

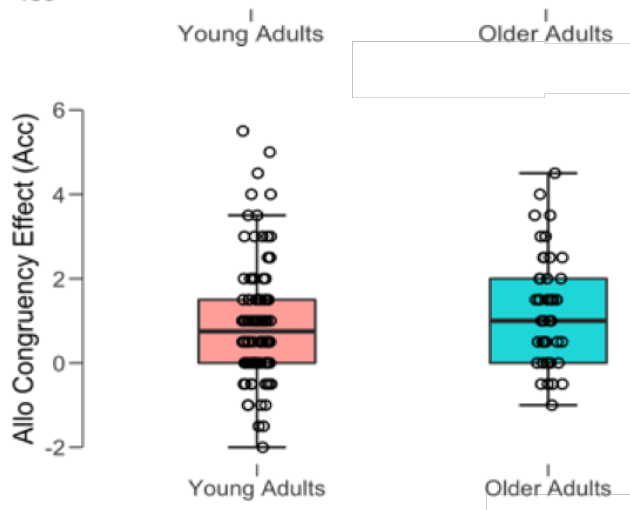

Figure 5. Level 2 visual perspective taking. Congruency effect refers to the difference between congruent and incongruent trials and is calculated for both response time and accuracy. Very strong evidence was found for a greater intrusion of the allocentric perspective into the egocentric, as indexed by a greater congruency effect on response time during egocentric trials in older adults.

\subsection{Implicit visual perspective taking}

For response time, an implicit VPT effect was confirmed by an Agent $\mathrm{x}$ Congruency interaction, $B F_{\text {inc }}=8.116 \mathrm{e}+8$. This means that when answering from the egocentric perspective only, without any requirement to switch to the alternate perspective, subjects were slower when the number of balls was incongruent with the hypothetical perspective of the avatar in the scene but not for the non-agent control condition (traffic light).

\subsubsection{Effect of age on implicit VPT effect}

No interaction between Age Group $x$ Agent $x$ Congruency was identified, $B F_{\text {inc }}=0.182$. Simple effects analysis revealed response times were slower when the number of balls was incongruent with the hypothetical view of the avatar, $B F_{i n c}=3.446 e+6$. Surprisingly, the 
Visual Perspective Taking

opposite pattern was identified for the traffic light, with response times longer when congruent, $\mathrm{BF}_{\mathrm{inc}}=11.70$.

For accuracy, no Agent $x$ Congruency effect was identified, $B F_{\text {inc }}=0.406$ nor was an Age Group $\mathrm{x}$ Agent $\mathrm{x}$ Congruency interaction, $\mathrm{BF}_{\mathrm{inc}}=0.231$.

\subsubsection{Robustness of implicit visual perspective taking effect to task expectations}

The second analysis focused on whether the implicit effect increased in the second session when participants were aware of the task demands (switching from self to other) that were to follow. An independent measures t-test identified no difference for the implicit VPT effect for the avatar $(10.83 \vee 13.44), \mathrm{BF}_{\mathrm{inc}}=0.204$, whereas there was anecdotal evidence for reduced difference between congruent and incongruent scenes for the traffic light in the second session $(-9.59 v-1.58), \mathrm{BF}_{\mathrm{inc}}=1.531$.

\subsection{Association with other cognitive measures}

Switching cost and congruency effects on accuracy and response times for egocentric and allocentric conditions were correlated with executive and social cognitive measures. For conditions where a specific effect for the avatar or traffic light was identified, these were entered into separate correlation analyses. All correlations are provided in Table 3.

\subsubsection{Social cognition}

There was moderate support for a correlation between the social emotional cognition task from the CogState and the congruency effect on accuracy during the allocentric conditions of both the level one and level two VPT task, $r=-0.209, B_{10}=3.120$ and $r=-0.244, B_{10}=9.904$ respectively (see Figure 6). Those who scored higher on the SEC task had a smaller congruency effect indicating a greater ability to inhibit the egocentric perspective. Linear regression revealed no interaction between Age Group and SEC on the allocentric congruency effect on accuracy for level two $\mathrm{VPT}, \mathrm{BF}_{10}=0.306$, demonstrating a consistent relationship in both young and older adults. However, for level one VPT, an interaction between Age Group $x$ 
Social Emotional Cognition was identified, $\mathrm{BF}_{\mathrm{inc}}=7.131$. This was explained by a strong negative correlation in the young adults, $\mathrm{r}=-0.344, \mathrm{BF}_{10}=119.5$ and no correlation in the older adults, $\mathrm{r}=0.142, \mathrm{BF}_{10}=0.283$. No significant correlations were found for the Reading the Mind in the Eyes task with any of the VPT measures.

\section{Level One VPT}

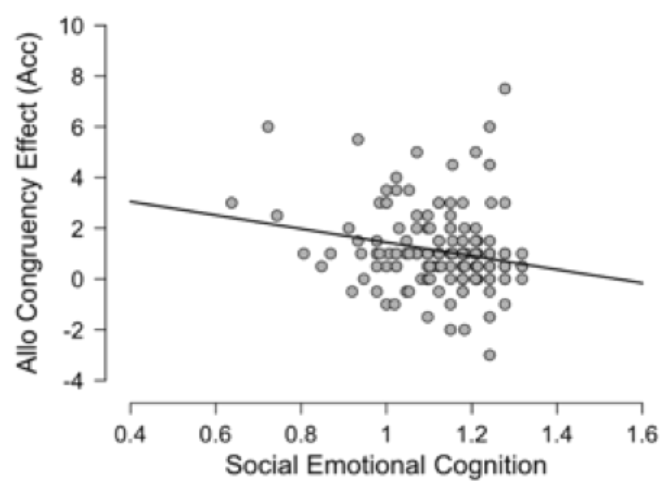

Level Two VPT

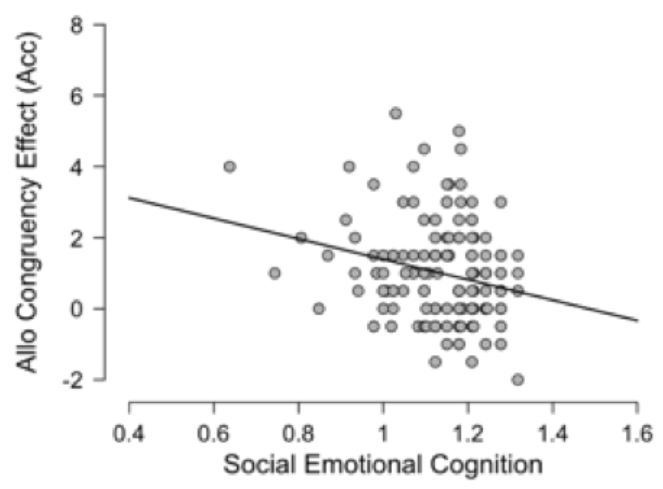

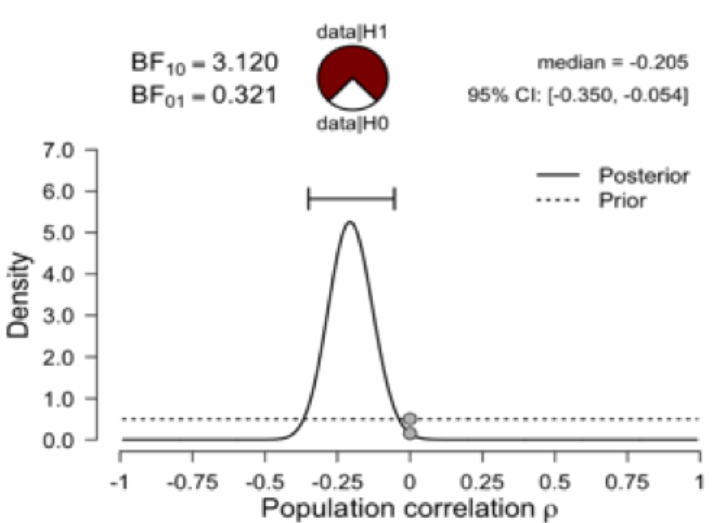

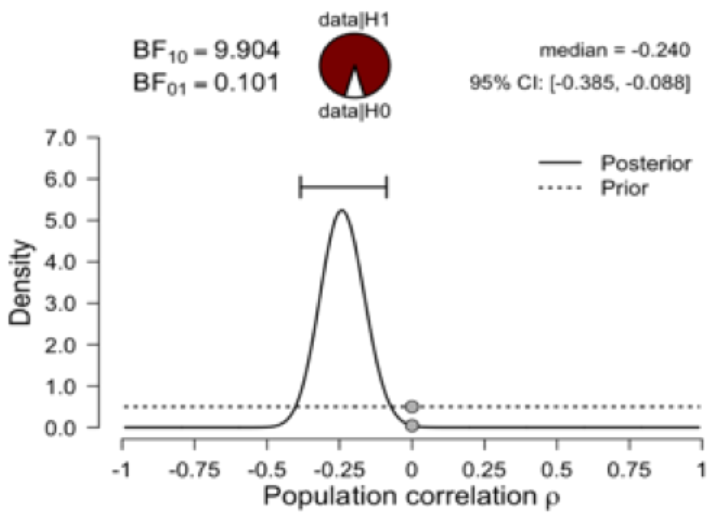

Figure 6. Congruency effect on accuracy for both level one and two VPT correlated with accuracy on the Social-Emotional Cognition Test. Subjects who showed better inhibition of the egocentric perspective performed better on the Social-Emotional Cognition Test. Prior and posterior distributions, the median effect size and a 95\% credible interval are provided. The pie charts provide a visual representation of the evidence for the null or alternate model.

\subsubsection{Executive abilities}

Response times for switching between egocentric and allocentric perspectives for both level one and level two VPT tasks had very strong to extreme evidence for a correlation with 1back $R T, r=0.285, B F_{10}=51.94$ and $r=0.379, B F_{10}=9958.19$, respectively (see Figure 7). Likewise, level one and two allocentric switch cost RTs correlated with the Stroop Effect, $\mathrm{r}=0.230, \mathrm{BF}_{10}=6.89$ and $\mathrm{r}=0.340, \mathrm{BF}_{10}=1022.86$ respectively. As 1-back $\mathrm{RT}$ was slower and 
the Stroop Effect was greater in older adults (see Table 1.), a regression model including 1back RT, Stroop Effect, and Age Group was calculated to assess whether age group remained a significant predictor of switching cost. For level one VPT, extreme evidence remained for Age Group, $\mathrm{BF}_{\text {inc }}=1.732 \mathrm{e}+15$, with evidence for a null effect of 1-back $\mathrm{RT}, \mathrm{BF}$ inc $=0.488$, and Stroop Effect, $\mathrm{BF}_{\mathrm{inc}}=0.067$. Interactions between Age Group $\times 1$-back $\mathrm{RT}, \mathrm{BF}$ inc $=0.223$ and Age Group x Stroop Effect, $\mathrm{BF}_{\text {inc }}=0.035$ were also not supported. For level two VPT Allocentric switch cost $\mathrm{RT}$, Age Group remained a predictor, $\mathrm{BF}_{\mathrm{inc}}=4.763 \mathrm{e}+6$ as did 1-back $\mathrm{RT}, \mathrm{BF}$ inc $=$ 11.013. Stroop Effect had no effect, $B F_{\text {inc }}=0.702$. There were no interactions between Age Group x 1-back RT, BF inc $=0.853$ or Age Group $\times$ Stroop Effect, $B F_{i n c}=0.612$.

\section{Level One VPT}
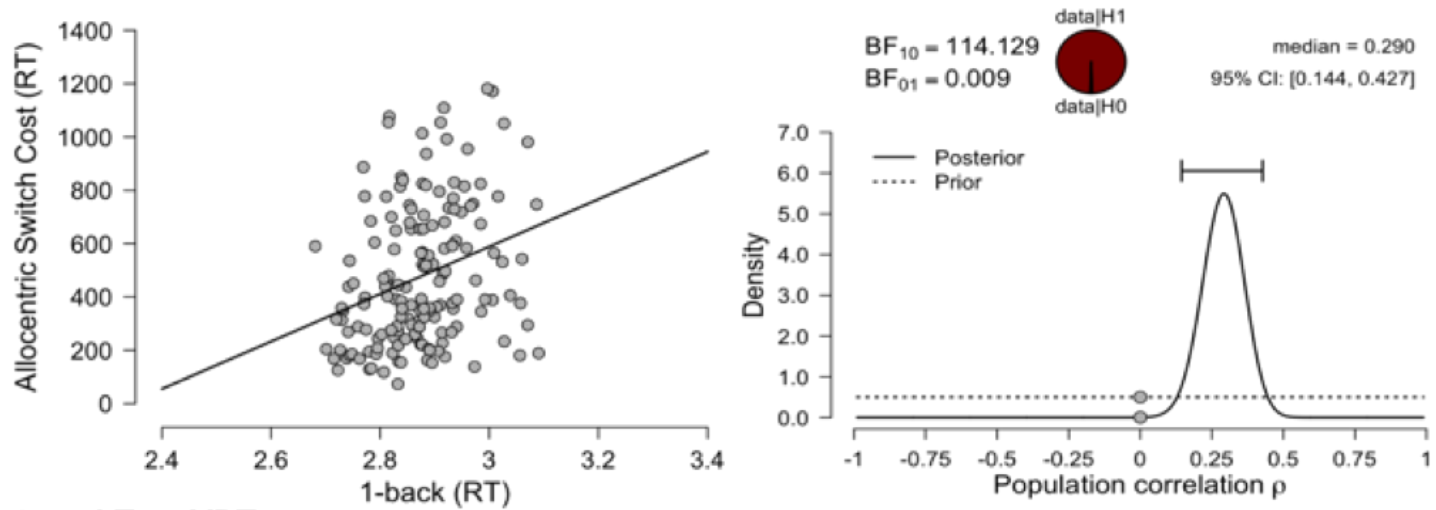

\section{Level Two VPT}
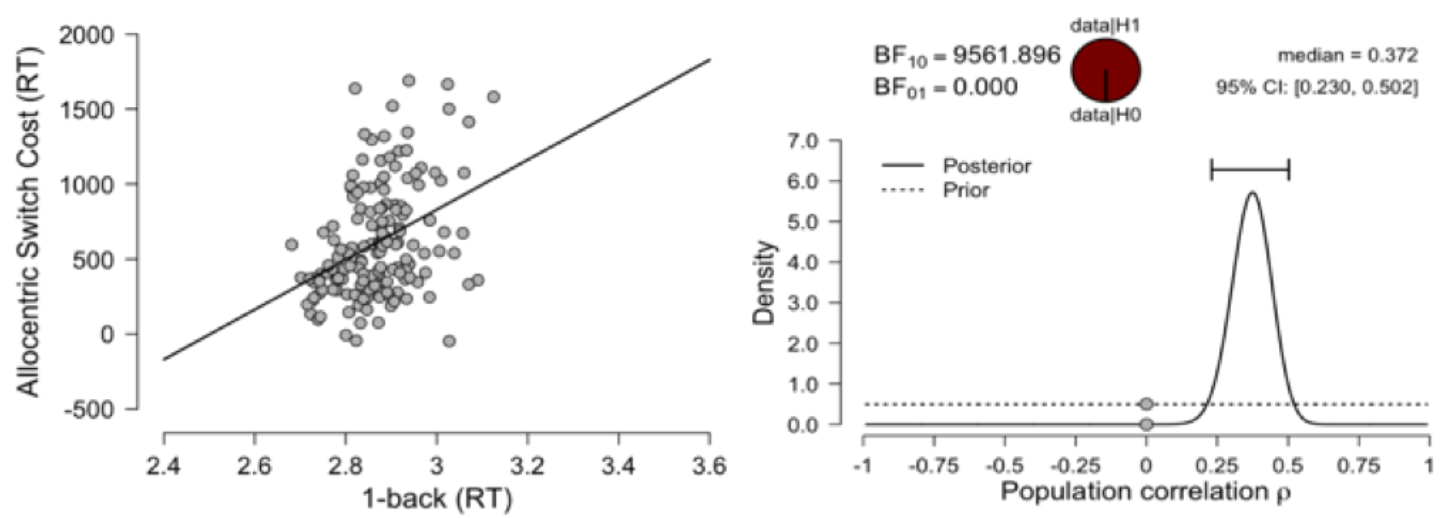

Figure 7. Switch cost on reaction time for both level one and two VPT correlated with 1-back response speed. Subjects who responded slower on the 1-back had a greater cost of switching to the allocentric perspective. Prior and posterior distributions, the median effect size and a $95 \%$ credible interval are provided. The pie charts provide a visual representation of the evidence for the null or alternate model. 
Level one egocentric congruency effect on RT correlated with 1-back RT, $r=0.334, B F_{10}=$ 1159.58 (see Figure 8) and 2-back accuracy, $r=-0.268, B F_{10}=32.72$. A regression model including 1-back RT and 2-back accuracy was computed and found only 1-back RT contributed to the model, $\mathrm{BF}_{\mathrm{inc}}=47.347$. There was no evidence for an effect of 2-back accuracy, $B F_{i n c}=$ 0.925, although this is only anecdotal evidence in favour of the null model. There was no correlation between level two egocentric congruency effect on RT and 1-back RT.
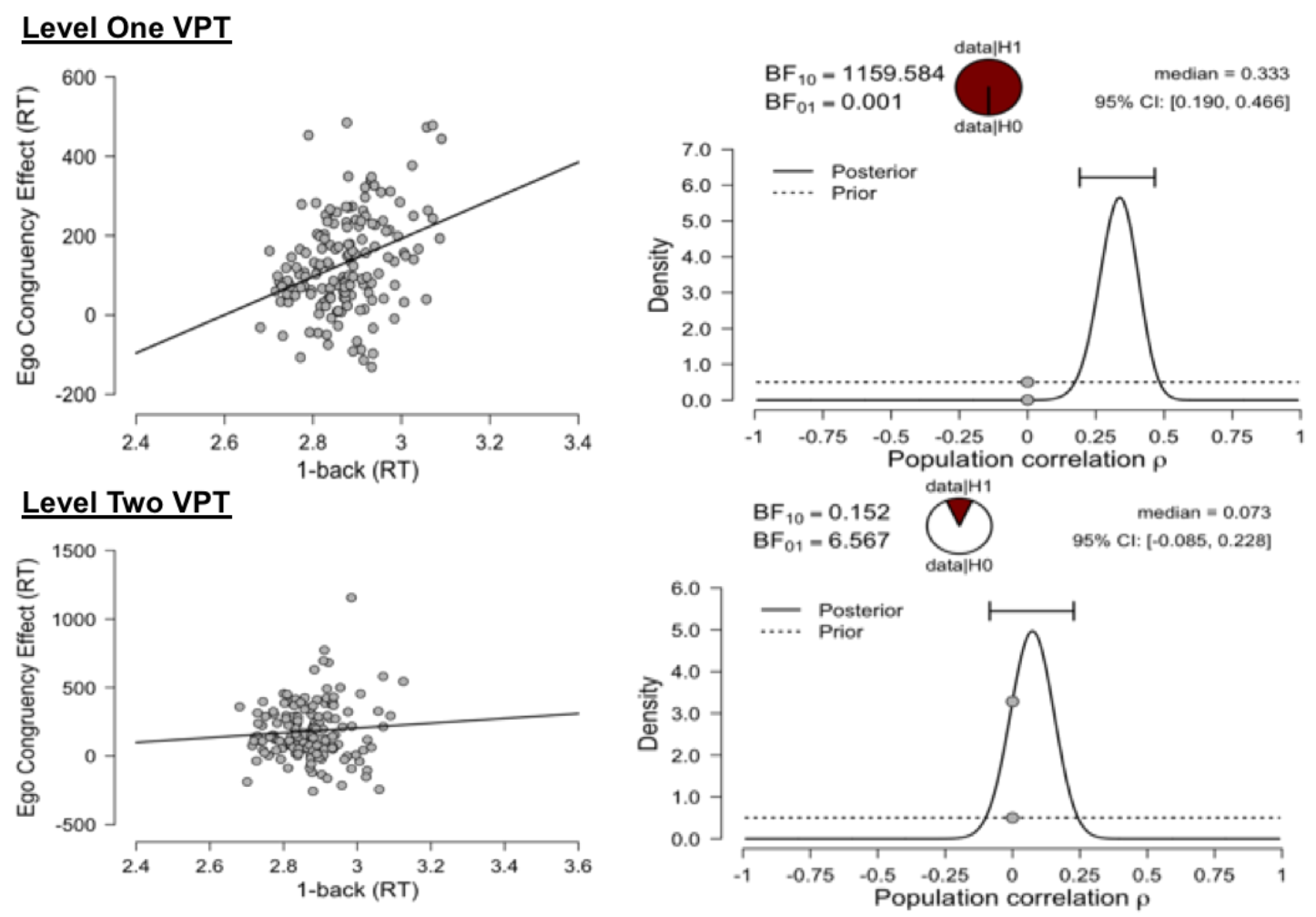

Figure 8. Egocentric congruency effect on RT correlated with 1-back RT for the level one but not the level two VPT task. Those who performed better on the 1-back had a smaller congruency effect on RT. Prior and posterior distributions as well as $95 \%$ confidence intervals are provided. The pie charts provide a visual representation of the evidence for the null or alternate model.

Separate correlations were computed for the avatar and traffic light for the VPT conditions that had a significant effect of Agent type. For the level one allocentric congruency effect on RT, strong evidence was identified for the correlation between the congruency effect with the avatar and 1-back RT, $r=0.252, \mathrm{BF}_{10}=15.482$ (see Figure 9) with anecdotal evidence for a correlation with 2-back accuracy and the Stroop Effect, $r=-0.197, B_{10}=2.160$ and $r=0.183$, $\mathrm{BF}_{10}=1.424$ respectively. For the level two egocentric congruency effect on accuracy, 
anecdotal evidence was identified for the correlation between the congruency effect with the avatar and 1-back RT, $r=0.200, B_{10}=2.092$. No significant correlations were identified for the traffic light condition.
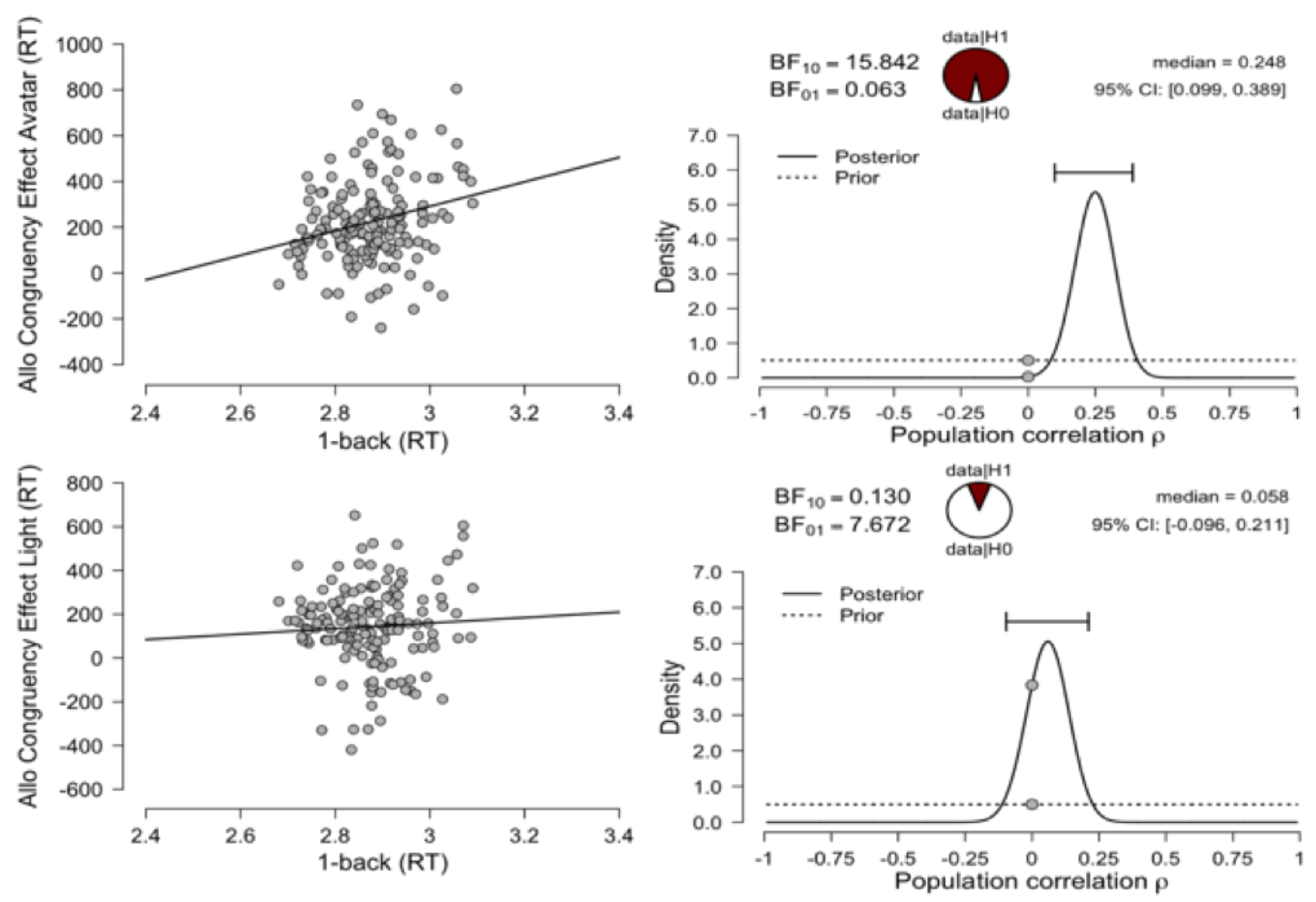

Figure 9. Allocentric congruency effect on RT during level one VPT when taking the perspective of the avatar, correlated with 1-back RT such that those who had a greater congruency effect were slower on the 1-back. No such correlation was identified when answering from the position of the light. Prior and posterior distributions, the median effect size and a $95 \%$ credible interval are provided. The pie charts provide a visual representation of the evidence for the null or alternate model.

For the implicit VPT, anecdotal evidence was identified for a correlation between the avatar congruency effect and Stroop Effect, $r=0.182, B_{10}=1.558$ (see Figure 10). The evidence for correlation with the light congruency effect all favoured the null model.

All other correlations received anecdotal to strong support in favour of the null model However, anecdotal support was found for a correlation between set-switching and egocentric congruency effect on $\mathrm{RT}, \mathrm{r}=0.178, \mathrm{BF}_{10}=1.167$ and between switch cost accuracy and 1-back RT for the level one VPT task, $\mathrm{r}=-0.186, \mathrm{BF}_{10}=1.532$. 

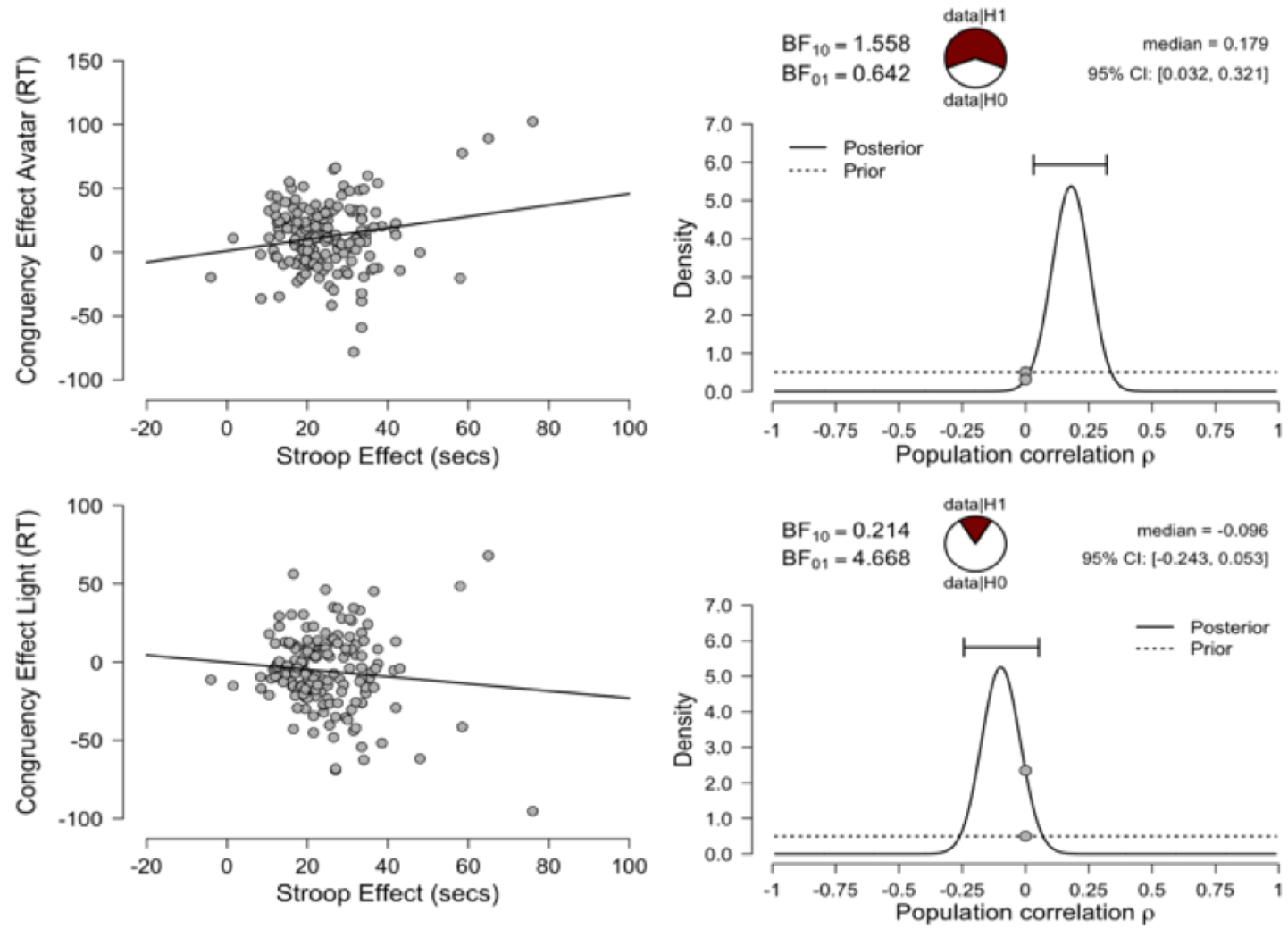

Figure 10. Implicit VPT effect for the avatar correlated with Stroop Effect. Subjects with a greater implicit VPT effect had a greater Stroop Effect. No correlation was identified when a light was in the scene. Prior and posterior distributions, the median effect size and a 95\% credible interval are provided. The pie charts provide a visual representation of the evidence for the null or alternate model. 
Table 3. Correlation between visual perspective taking measures and executive tasks.

\begin{tabular}{|c|c|c|c|c|c|c|c|}
\hline & & $\begin{array}{l}\text { 1-back } \\
\text { RT }\end{array}$ & $\begin{array}{l}\text { 2-back } \\
\text { Acc }\end{array}$ & $\begin{array}{l}\text { Set- } \\
\text { Switching }\end{array}$ & $\begin{array}{l}\text { Stroop } \\
\text { Effect }\end{array}$ & RMET & $\begin{array}{l}\text { Soc-Emo } \\
\text { Cognition }\end{array}$ \\
\hline \multicolumn{8}{|l|}{ Implicit VPT } \\
\hline Avatar CE (RT) & $\begin{array}{l}r \\
\mathrm{BF}_{10}\end{array}$ & $\begin{array}{l}0.022 \\
0.100\end{array}$ & $\begin{array}{l}0.014 \\
0.098\end{array}$ & $\begin{array}{l}-0.032 \\
0.106\end{array}$ & $\begin{array}{l}0.182 \\
1.558\end{array}$ & $\begin{array}{l}-0.033 \\
0.105\end{array}$ & $\begin{array}{l}-0.038 \\
0.109\end{array}$ \\
\hline Avatar CE (Acc) & $\begin{array}{l}r \\
\mathrm{BF}_{10}\end{array}$ & $\begin{array}{l}0.020 \\
0.100\end{array}$ & $\begin{array}{l}0.009 \\
0.097\end{array}$ & $\begin{array}{l}0.046 \\
0.115\end{array}$ & $\begin{array}{l}-0.098 \\
0.214\end{array}$ & $\begin{array}{l}-0.060 \\
0.130\end{array}$ & $\begin{array}{l}-0.112 \\
0.270\end{array}$ \\
\hline Light CE (RT) & $\begin{array}{l}r \\
\mathrm{BF}_{10}\end{array}$ & $\begin{array}{l}0.000 \\
0.097\end{array}$ & $\begin{array}{l}-0.043 \\
0.112\end{array}$ & $\begin{array}{l}-0.018 \\
0.100\end{array}$ & $\begin{array}{l}-0.098 \\
0.214\end{array}$ & $\begin{array}{l}-0.042 \\
0.111\end{array}$ & $\begin{array}{l}-0.082 \\
0.168\end{array}$ \\
\hline Light CE (AcC) & $\begin{array}{l}\mathrm{r} \\
\mathrm{BF}_{10}\end{array}$ & $\begin{array}{l}-0.148 \\
0.597\end{array}$ & $\begin{array}{l}0.119 \\
0.314\end{array}$ & $\begin{array}{l}-0.013 \\
0.099\end{array}$ & $\begin{array}{l}-0.147 \\
0.587\end{array}$ & $\begin{array}{l}0.081 \\
0.166\end{array}$ & $\begin{array}{l}0.125 \\
0.350\end{array}$ \\
\hline \multicolumn{8}{|l|}{ Level 1 VPT } \\
\hline Ego CE (RT) & $\begin{array}{l}r \\
\mathrm{BF}_{10}\end{array}$ & $\begin{array}{l}0.334 \\
1159.584\end{array}$ & $\begin{array}{l}-0.268 \\
32.723\end{array}$ & $\begin{array}{l}0.178 \\
1.167\end{array}$ & $\begin{array}{l}0.111 \\
0.261\end{array}$ & $\begin{array}{l}-0.150 \\
0.586\end{array}$ & $\begin{array}{l}-0.139 \\
0.450\end{array}$ \\
\hline Ego CE (Acc) & $\begin{array}{l}\mathrm{r} \\
\mathrm{BF}_{10}\end{array}$ & $\begin{array}{l}0.153 \\
0.620\end{array}$ & $\begin{array}{l}-0.157 \\
0.686\end{array}$ & $\begin{array}{l}0.135 \\
0.404\end{array}$ & $\begin{array}{l}0.091 \\
0.189\end{array}$ & $\begin{array}{l}-0.050 \\
0.120\end{array}$ & $\begin{array}{l}-0.030 \\
0.106\end{array}$ \\
\hline Allo CE Avatar (RT) & $\begin{array}{l}r \\
\mathrm{BF}_{10}\end{array}$ & $\begin{array}{l}0.252 \\
15.842\end{array}$ & $\begin{array}{l}-0.197 \\
2.160\end{array}$ & $\begin{array}{l}0.014 \\
0.101\end{array}$ & $\begin{array}{l}0.183 \\
1.424\end{array}$ & $\begin{array}{l}-0.054 \\
0.124\end{array}$ & $\begin{array}{l}-0.061 \\
0.133\end{array}$ \\
\hline Allo CE Light (RT) & $\begin{array}{l}r \\
\mathrm{BF}_{10}\end{array}$ & $\begin{array}{l}0.059 \\
0.130\end{array}$ & $\begin{array}{l}-0.088 \\
0.181\end{array}$ & $\begin{array}{l}0.052 \\
0.123\end{array}$ & $\begin{array}{l}0.002 \\
0.099\end{array}$ & $\begin{array}{l}0.065 \\
0.137\end{array}$ & $\begin{array}{l}-0.012 \\
0.100\end{array}$ \\
\hline Allo CE (Acc) & $\begin{array}{l}r \\
\mathrm{BF}_{10}\end{array}$ & $\begin{array}{l}0.081 \\
0.165\end{array}$ & $\begin{array}{l}-0.129 \\
0.366\end{array}$ & $\begin{array}{l}0.090 \\
0.186\end{array}$ & $\begin{array}{l}-0.021 \\
0.102\end{array}$ & $\begin{array}{l}-0.106 \\
0.239\end{array}$ & $\begin{array}{l}-0.209 \\
3.120\end{array}$ \\
\hline Switch Cost (RT) & $\begin{array}{l}r \\
\mathrm{BF}_{10}\end{array}$ & $\begin{array}{l}0.295 \\
114.129\end{array}$ & $\begin{array}{l}-0.117 \\
0.289\end{array}$ & $\begin{array}{l}-0.122 \\
0.312\end{array}$ & $\begin{array}{l}0.230 \\
6.893\end{array}$ & $\begin{array}{l}-0.110 \\
0.258\end{array}$ & $\begin{array}{l}-0.047 \\
0.118\end{array}$ \\
\hline Switch Cost (Acc) & $\begin{array}{l}\mathrm{r} \\
\mathrm{BF}_{10}\end{array}$ & $\begin{array}{l}-0.186 \\
1.532\end{array}$ & $\begin{array}{l}0.035 \\
0.109\end{array}$ & $\begin{array}{l}0.026 \\
0.105\end{array}$ & $\begin{array}{l}-0.091 \\
0.188\end{array}$ & $\begin{array}{l}-0.050 \\
0.120\end{array}$ & $\begin{array}{l}-0.167 \\
0.882\end{array}$ \\
\hline \multicolumn{8}{|l|}{ Level 2 VPT } \\
\hline Ego CE (RT) & $\begin{array}{l}r \\
\mathrm{BF}_{10}\end{array}$ & $\begin{array}{l}0.074 \\
0.152\end{array}$ & $\begin{array}{l}-0.024 \\
0.106\end{array}$ & $\begin{array}{l}0.013 \\
0.103\end{array}$ & $\begin{array}{l}0.108 \\
0.244\end{array}$ & $\begin{array}{l}-0.021 \\
0.104\end{array}$ & $\begin{array}{l}0.010 \\
0.102\end{array}$ \\
\hline Ego CE Avatar (Acc) & $\begin{array}{l}r \\
\mathrm{BF}_{10}\end{array}$ & $\begin{array}{l}0.200 \\
2.092\end{array}$ & $\begin{array}{l}-0.083 \\
0.169\end{array}$ & $\begin{array}{l}0.155 \\
0.602\end{array}$ & $\begin{array}{l}0.141 \\
0.456\end{array}$ & $\begin{array}{l}-0.035 \\
0.110\end{array}$ & $\begin{array}{l}-0.080 \\
0.163\end{array}$ \\
\hline Ego CE Light (Acc) & $\begin{array}{l}r \\
\mathrm{BF}_{10}\end{array}$ & $\begin{array}{l}0.018 \\
0.104\end{array}$ & $\begin{array}{l}-0.080 \\
0.163\end{array}$ & $\begin{array}{l}0.159 \\
0.668\end{array}$ & $\begin{array}{l}0.126 \\
0.333\end{array}$ & $\begin{array}{l}-0.025 \\
0.105\end{array}$ & $\begin{array}{l}0.040 \\
0.114\end{array}$ \\
\hline Allo CE (RT) & $\begin{array}{l}r \\
\mathrm{BF}_{10}\end{array}$ & $\begin{array}{l}0.111 \\
0.253\end{array}$ & $\begin{array}{l}-0.136 \\
0.406\end{array}$ & $\begin{array}{l}-0.012 \\
0.103\end{array}$ & $\begin{array}{l}0.015 \\
0.103\end{array}$ & $\begin{array}{l}-0.166 \\
0.833\end{array}$ & $\begin{array}{l}-0.085 \\
0.174\end{array}$ \\
\hline Allo CE (Acc) & $\begin{array}{l}r \\
\mathrm{BF}_{10}\end{array}$ & $\begin{array}{l}-0.098 \\
0.209\end{array}$ & $\begin{array}{l}-0.011 \\
0.102\end{array}$ & $\begin{array}{l}0.007 \\
0.102\end{array}$ & $\begin{array}{l}0.123 \\
0.315\end{array}$ & $\begin{array}{l}0.047 \\
0.119\end{array}$ & $\begin{array}{l}-0.244 \\
9.904\end{array}$ \\
\hline Switch Cost (RT) & $\begin{array}{l}r \\
\mathrm{BF}_{10}\end{array}$ & $\begin{array}{l}0.377 \\
9561.896\end{array}$ & $\begin{array}{l}-0.113 \\
0.261\end{array}$ & $\begin{array}{l}-0.098 \\
0.207\end{array}$ & $\begin{array}{l}0.340 \\
1022.864\end{array}$ & $\begin{array}{l}-0.054 \\
0.125\end{array}$ & $\begin{array}{l}0.028 \\
0.107\end{array}$ \\
\hline Switch Cost (Acc) & $\begin{array}{l}r \\
\mathrm{BF}_{10}\end{array}$ & $\begin{array}{l}0.042 \\
0.115\end{array}$ & $\begin{array}{l}0.014 \\
0.103\end{array}$ & $\begin{array}{l}-0.009 \\
0.102\end{array}$ & $\begin{array}{l}0.098 \\
0.209\end{array}$ & $\begin{array}{l}0.009 \\
0.101\end{array}$ & $\begin{array}{l}-0.148 \\
0.523\end{array}$ \\
\hline
\end{tabular}

VPT= Visual perspective taking; RMET $=$ Reading the Mind in the Eyes; Ego = Egocentric; Allo = Allocentric; RT = Response Time; $\mathrm{Acc}=$ Accuracy; $\mathrm{CE}=$ Congruency Effect 
Visual Perspective Taking

\section{Discussion}

Using a novel visual perspective taking (VPT) task, we provide the first evidence for an impairment in switching to the allocentric visual perspective in older adults. Moreover, we demonstrate a greater congruency effect in older adults during egocentric judgements during a level two VPT task, indicating a greater intrusion of other perspectives in tasks requiring mental rotation. We provide further evidence for the association between VPT measures and measures of executive and social cognition. Finally, we demonstrate an implicit VPT effect that is consistent between sessions when the participant is naïve or aware of the upcoming demands to switch between self and other perspectives. The implicit VPT effect was observed to the same extent in both younger and older adults.

Compared to younger adults, older adults may have reduced capacity to represent the mental states of others (Charlton, Barrick, Markus, \& Morris, 2009; Henry et al., 2013; Moran, 2013; Moran, Jolly, \& Mitchell, 2012; Rakoczy, Harder-Kasten, \& Sturm, 2012). Similarly, it has been demonstrated that older adults are less able to switch to the alternative perspective during interactive discourse (Long, Horton, Rohde, \& Sorace, 2018), favour the self-perspective (Mattan et al, 2017) and show a greater empathic egocentricity bias (Riva et al., 2016). In the current study, we provide the first evidence that this difficulty extends to both level one and two explicit VPT. It has been suggested that when adopting another's perspective, people use their own perspective as an anchor and must adjust to adopt the alternate perspective (Epley, Keysar, Van Boven, \& Gilovich, 2004). If the egocentric is the default stance, cognitive effort would be required to switch from the egocentric, inhibit the egocentric perspective, and hold in working memory the task demands. This is supported in the current study by the observation that allocentric switching ability across both level one and two visual VPT correlated with working memory response time and response inhibition, with working memory remaining significant in a regression model. An association with working memory suggests that switching to the allocentric perspective places demand on processing resources (Salthouse, 1996) and the reduced switching speed in older adults provides evidence for a resource-deficit hypothesis of aging (Kahneman, 1973). However, we show that although working memory contributes to age-related differences, significant variance between young and older adults remained with working memory in the model. Therefore, working memory 
deficits alone are not sufficient to explain slower allocentric perspective switching in older adults and difficulty with taking the allocentric perspective reflects a specific deficit that may contribute to higher-order social deficits.

The egocentric congruency effect correlated with both working memory response time and updating ability for the level one VPT task but not level two. This suggests different cognitive processes are associated with the two tasks. This is of interest for aging as the older adults had a greater congruency effect only in the level two task. A greater congruency effect during egocentric perspective trials is thought to represent automatic perspective calculation ( Surtees, Samson, \& Apperly, 2016). As there was no difference during allocentric perspective taking, with older adults actually slightly less influenced by incongruent egocentric perspective, it suggests that the results are not due to perspective selection (Ramsey et al., 2013; Samson et al., 2010). Level two tasks are thought to rely on a more embodied mental rotation (Kessler \& Rutherford, 2010; Michelon \& Zacks, 2006). In other words, in order to make a laterality judgment, people tend to mentally rotate their self-perspective to that of the allocentric position. Therefore, the fact that older adults show a greater egocentric congruency effect may reflect a weakened embodied sense of self (Costello \& Bloesch, 2017) that erroneously mentally rotates to an alternate perspective when not required. Previous research has found that older adults are slower and make more errors when asked to mentally rotate objects, especially the human body (Devlin \& Wilson, 2010). However, to the authors knowledge, this is the first study to show that older adults face the additional problems of rotating into an alternate location when required as well as inhibit this rotation when it is not required. Further research is required to understand the links with embodied cognition or other potential explanations such as the effects of strategy (Lemaire, 2010) or task difficulty (McDowd \& Craik, 1988) on the greater congruency effect in level two VPT in older adults.

VPT has been conceptualized as a precursor to higher-order social functions such as theory of mind with level two considered to be closely related (Hamilton et al., 2009). The congruency effect on accuracy during allocentric judgments of both the level one and two tasks correlated with social cognition (i.e. CogState Social-Emotional Cognition task). The congruency effect reflects the ability to inhibit the egocentric perspective when answering from the allocentric, 
which may be a cognitive process underpinning social emotional understanding. However, the association did not extend to affective ToM as measured by the Reading the Mind in the Eyes Test. A stronger correlation between level one allocentric VPT congruency effect on accuracy and SEC suggests that young and older adults rely to some extent on different underlying cognitive processes to complete level one VPT tasks. This may reflect a different strategy to complete level one VPT tasks which is common with several cognitive tasks and ageing (Lemaire, 2010). Older adults may rely more on mental rotation rather than embodied transformation as has been suggested as a reason for differences on VPT tasks in normal developing children and those with autism (Pearson, Marsh, Ropar, \& Hamilton, 2016), but this needs investigating in future studies. Another possibility is that older adults approach the task using a "line of sight" judgement whereby they track from their own perspective to that of the avatar/traffic light and discount balls occluded by a bin or behind the avatar/traffic light. The stronger correlation with SEC in younger adults may represent a greater reliance on embodied rotation which is closely related to higher-order social cognition (Pearson et al., 2013).

Another important finding in our study was the demonstration of an implicit VPT effect. Previous studies into implicit VPT have predominantly relied on the Dot Task that requires participants to shift their attention to the left or right of the scene. This "attention grab" has been suggested as a possible explanation of the observed implicit VPT effect, with subsequent studies demonstrating that an arrow achieves an identical effect (Santiesteban et al., 2014). In the current study, the gaze of the participant was not directed laterally and therefore removed the confound present in the Dot Task. We identified an implicit VPT effect that was small ( 12.2 msecs) but with extreme evidence that was consistent across sessions where the subject was both naïve or aware of upcoming task demands. A correlation was identified between the implicit VPT effect and the Stroop Effect suggesting that the subject must inhibit the pre-potent response of taking the avatar's perspective in a similar manner to inhibiting word reading during the incongruent Stroop condition. It should be noted that the correlation only resulted in anecdotal evidence and this will need confirmation in future studies. The results provide complimentary evidence to previous research demonstrating that cognitive load impairs implicit belief tracking in higher-order mentalizing tasks (Schneider, Lam, Bayliss, \& Dux, 2012). During the explicit VPT tasks, the two conditions with a difference between 
congruency effects for the avatar compared to the traffic light, only the avatar congruency effect correlated with executive measures. In the level one task, only the allocentric avatar RT congruency effect correlated with executive ability, which may be explained by a closer cognitive "mapping" between the egocentric perspective and the perspective of the avatar which in turn requires greater inhibition due to shared cognitive resources.

The current study is limited to the VPT task and executive and social cognitive measures used. Level two VPT has been measured using a number of methods (Pearson et al., 2013) and the task employed here is a simple laterality task that is solvable using a number of strategies. It should be noted that congruency was always based on level one information (number of balls seen) with the laterality question used solely to induce mental rotation. Future research should include other measures of VPT level two that encourage greater embodied rotation. That said, the age effects demonstrate that the laterality question was sufficient to affect strategy or processing of information between level one and two VPT. Although we found no correlation with affective ToM, it is possible that VPT only correlates with cognitive ToM measures and these should be included in future research. We have also taken a categorical, cross-sectional approach to assessing age-related effects. As executive and social ability declines with age, a continuous approach will provide more detailed understanding of agerelated decline in VPT ability and the relationship with other cognitive functioning as well as address changes that are likely to occur between 55 to 80 years of age. However, this is an important initial study that demonstrates ageing effects on VPT.

In summary, older adults are impaired at taking the allocentric perspective and show a greater intrusion from the allocentric perspective in tasks requiring mental rotation. Although VPT correlates with executive and social cognition, perspective taking ability appears to be a specific deficit associated with advanced age. Perspective taking in older adults requires further investigation and may provide insight into difficulties with higher-order social cognitive tasks and social interactions in general. Understanding the cognitive architecture underpinning difficulties in social interaction will assist remediation programs aimed at improving the social lives of older adults. 
Visual Perspective Taking

\section{Acknowledgements}

The authors acknowledge all participants for their time and efforts in completing the study. We also acknowledge Dr Ilvana Dzafic for her assistance with coding the tasks.

\section{Conflicts of Interest}

None declared

Funding

This work was supported by a Future Fellowship grant [FT120100608] and a strategic seedfunding grant from the University of Queensland, awarded to Marcus Meinzer.

\section{Author Contributions}

A.K.M and M.M conceived the experiment. A.K.M designed the experiment. A.K.M, G.P, I.D, P.S., \& J. H collected the data. A.K.M analyzed the data. A.K.M. wrote the manuscript. All authors edited the manuscript. 


\section{References}

Albinet, C. T., Boucard, G., Bouquet, C. A., \& Audiffren, M. (2012). Processing speed and executive functions in cognitive aging: how to disentangle their mutual relationship? Brain Cogn, 79(1), 1-11. doi: 10.1016/j.bandc.2012.02.001

Apperly, I. A., \& Butterfill, S. A. (2009). Do humans have two systems to track beliefs and belief-like states? Psychol Rev, 116(4), 953-970. doi: 10.1037/a0016923

Bailey, P. E., Henry, J. D., \& Von Hippel, W. (2008). Empathy and social functioning in late adulthood. Aging Ment Health, 12(4), 499-503. doi: 10.1080/13607860802224243

Baron-Cohen, S., Wheelwright, S., Hill, J., Raste, Y., \& Plumb, I. (2001). The "Reading the Mind in the Eyes" Test revised version: a study with normal adults, and adults with Asperger syndrome or high-functioning autism. J Child Psychol Psychiatry, 42(2), 241251.

Baron-Cohen, S., Wheelwright, S., Skinner, R., Martin, J., Clubley, E. (2001). The autismspectrum quotient ( $A Q$ ): evidence from Asperger syndrome/high-functioning autism, males and females, scientists and mathematicians. Journal of Autism and Developmental Disorders, 31(1), 5-17.

Borella, E., Carretti, B., \& De Beni, R. (2008). Working memory and inhibition across the adult life-span. Acta Psychol (Amst), 128(1), 33-44. doi: 10.1016/j.actpsy.2007.09.008

Bugg, J. M., DeLosh, E. L., Davalos, D. B., \& Davis, H. P. (2007). Age differences in Stroop interference: contributions of general slowing and task-specific deficits. Neuropsychol Dev Cogn B Aging Neuropsychol Cogn, 14(2), 155-167. doi: 10.1080/138255891007065

Carlson, S. M., \& Moses, L. J. (2001). Individual differences in inhibitory control and children's theory of mind. Child Dev, 72(4), 1032-1053.

Charlton, R. A., Barrick, T. R., Markus, H. S., \& Morris, R. G. (2009). Theory of mind associations with other cognitive functions and brain imaging in normal aging. Psychol Aging, 24(2), 338-348. doi: 10.1037/a0015225

Conway, J. R., Lee, D., Ojaghi, M., Catmur, C., \& Bird, G. (2017). Submentalizing or mentalizing in a Level 1 perspective-taking task: A cloak and goggles test. J Exp Psychol Hum Percept Perform, 43(3), 454-465. doi: 10.1037/xhp0000319

Costello, M. C., \& Bloesch, E. K. (2017). Are Older Adults Less Embodied? A Review of Age Effects through the Lens of Embodied Cognition. Front Psychol, 8, 267. doi: 10.3389/fpsyg.2017.00267

Devlin, A. L., \& Wilson, P. H. (2010). Adult age differences in the ability to mentally transform object and body stimuli. Neuropsychol Dev Cogn B Aging Neuropsychol Cogn, 17(6), 709-729. doi: 10.1080/13825585.2010.510554

Epley, N., Keysar, B., Van Boven, L., \& Gilovich, T. (2004). Perspective taking as egocentric anchoring and adjustment. J Pers Soc Psychol, 87(3), 327-339. doi: 10.1037/00223514.87.3.327

Ferguson, H. J., Apperly, I., \& Cane, J. E. (2017). Eye tracking reveals the cost of switching between self and other perspectives in a visual perspective-taking task. Q J Exp Psychol (Hove), 70(8), 1646-1660. doi: 10.1080/17470218.2016.1199716

Frith, C. D., \& Frith, U. (2008). Implicit and explicit processes in social cognition. Neuron, 60(3), 503-510. doi: 10.1016/j.neuron.2008.10.032

Gelman, A., Hill, J., \& Yajima, M. (2012). Why we (usually) don't have to worry about multiple comparisons. Journal of Research on Educational Effectiveness, 5, 189-211. 
Gzesh, S. M., \& Surber, C. F. (1985). Visual perspective-taking skills in children. Child Dev, 56(5), 1204-1213.

Hamilton, A. F., Brindley, R., \& Frith, U. (2009). Visual perspective taking impairment in children with autistic spectrum disorder. Cognition, 113(1), 37-44. doi: 10.1016/j.cognition.2009.07.007

Henry, J. D., Phillips, L. H., Ruffman, T., \& Bailey, P. E. (2013). A meta-analytic review of age differences in theory of mind. Psychol Aging, 28(3), 826-839. doi: 10.1037/a0030677

Hess, T. M. (2014). Selective Engagement of Cognitive Resources: Motivational Influences on Older Adults' Cognitive Functioning. Perspect Psychol Sci, 9(4), 388-407. doi: 10.1177/1745691614527465

Kahneman, D. (1973). Attention and effort. Englewood Cliffs, NJ: Prentice Hall.

Kessler, K., \& Rutherford, H. (2010). The Two Forms of Visuo-Spatial Perspective Taking are Differently Embodied and Subserve Different Spatial Prepositions. Front Psychol, 1, 213. doi: $10.3389 /$ fphys.2010.00213

Kovacs, A. M., Teglas, E., \& Endress, A. D. (2010). The social sense: susceptibility to others' beliefs in human infants and adults. Science, 330(6012), 1830-1834. doi: 10.1126/science.1190792

Lemaire, P. (2010). Cognitive strategy variations during aging. Current Directions in Psychological Science, 19(6), 363-369.

Long, M. R., Horton, W. S., Rohde, H., \& Sorace, A. (2018). Individual differences in switching and inhibition predict perspective-taking across the lifespan. Cognition, 170, 25-30. doi: 10.1016/j.cognition.2017.09.004

Martin, A. K., Dzafic, I., Ramdave, S., \& Meinzer, M. (2017). Causal evidence for task-specific involvement of the dorsomedial prefrontal cortex in human social cognition. Soc Cogn Affect Neurosci. doi: 10.1093/scan/nsx063

Martin, A. K., Huang, J., Hunold, A., \& Meinzer, M. (2017). Sex Mediates the Effects of HighDefinition Transcranial Direct Current Stimulation on "Mind-Reading". Neuroscience, 366, 84-94. doi: 10.1016/j.neuroscience.2017.10.005

Mattan, B. D., Quinn, K. A., Acaster, S. L., Jennings, R. M., \& Rotshtein, P. (2017). Prioritization of self-relevant perspectives in ageing. Q J Exp Psychol (Hove), 70(6), 1033-1052. doi: 10.1080/17470218.2015.1127399

McDowd, J. M., \& Craik, F. I. M. (1988). Effects of aging and task difficulty on divided attention performance. J Exp Psychol Hum Percept Perform, 14(2), 267-280. doi: 10.1037/0096-1523.14.2.267

Michelon, P., \& Zacks, J. M. (2006). Two kinds of visual perspective taking. Percept Psychophys, 68(2), 327-337.

Miyake, A., Friedman, N. P., Emerson, M. J., Witzki, A. H., Howerter, A., \& Wager, T. D. (2000). The unity and diversity of executive functions and their contributions to complex "Frontal Lobe" tasks: a latent variable analysis. Cogn Psychol, 41(1), 49-100. doi: 10.1006/cogp.1999.0734

Moran, J. M. (2013). Lifespan development: the effects of typical aging on theory of mind. Behav Brain Res, 237, 32-40. doi: 10.1016/j.bbr.2012.09.020

Moran, J. M., Jolly, E., \& Mitchell, J. P. (2012). Social-cognitive deficits in normal aging. J Neurosci, 32(16), 5553-5561. doi: 10.1523/JNEUROSCI.5511-11.2012

Pearson, A., Marsh, L., Ropar, D., \& Hamilton, A. (2016). Cognitive Mechanisms underlying visual perspective taking in typical and ASC children. Autism Res, 9(1), 121-130. doi: 10.1002/aur.1501 
Pearson, A., Ropar, D., \& Hamilton, A. F. (2013). A review of visual perspective taking in autism spectrum disorder. Front Hum Neurosci, 7, 652. doi: 10.3389/fnhum.2013.00652

Qureshi, A. W., Apperly, I. A., \& Samson, D. (2010). Executive function is necessary for perspective selection, not Level-1 visual perspective calculation: evidence from a dual-task study of adults. Cognition, 117(2), 230-236. doi: 10.1016/j.cognition.2010.08.003

Rakoczy, H., Harder-Kasten, A., \& Sturm, L. (2012). The decline of theory of mind in old age is (partly) mediated by developmental changes in domain-general abilities. $\mathrm{Br} \mathrm{J}$ Psychol, 103(1), 58-72. doi: 10.1111/j.2044-8295.2011.02040.x

Ramsey, R., Hansen, P., Apperly, I., \& Samson, D. (2013). Seeing it my way or your way: frontoparietal brain areas sustain viewpoint-independent perspective selection processes. J Cogn Neurosci, 25(5), 670-684. doi: 10.1162/jocn_a_00345

Riva, F., Triscoli, C., Lamm, C., Carnaghi, A., \& Silani, G. (2016). Emotional Egocentricity Bias Across the Life-Span. Front Aging Neurosci, 8, 74. doi: 10.3389/fnagi.2016.00074

Salthouse, T. (2012). Consequences of age-related cognitive declines. Annu Rev Psychol, 63, 201-226. doi: 10.1146/annurev-psych-120710-100328

Salthouse, T. A. (1996). The processing-speed theory of adult age differences in cognition. Psychol Rev, 103(3), 403-428.

Samson, D., Apperly, I. A., Braithwaite, J. J., Andrews, B. J., \& Bodley Scott, S. E. (2010). Seeing it their way: evidence for rapid and involuntary computation of what other people see. J Exp Psychol Hum Percept Perform, 36(5), 1255-1266. doi: 10.1037/a0018729

Santiesteban, I., Catmur, C., Hopkins, S. C., Bird, G., \& Heyes, C. (2014). Avatars and arrows: implicit mentalizing or domain-general processing? J Exp Psychol Hum Percept Perform, 40(3), 929-937. doi: 10.1037/a0035175

Schneider, D., Lam, R., Bayliss, A. P., \& Dux, P. E. (2012). Cognitive load disrupts implicit theory-of-mind processing. Psychol Sci, 23(8), 842-847. doi: $10.1177 / 0956797612439070$

Surtees, A., Apperly, I., \& Samson, D. (2013). The use of embodied self-rotation for visual and spatial perspective-taking. Front Hum Neurosci, 7, 698. doi: 10.3389/fnhum.2013.00698

Surtees, A., Samson, D., \& Apperly, I. (2016). Unintentional perspective-taking calculates whether something is seen, but not how it is seen. Cognition, 148, 97-105. doi: 10.1016/j.cognition.2015.12.010

Surtees, A. D., \& Apperly, I. A. (2012). Egocentrism and automatic perspective taking in children and adults. Child Dev, 83(2), 452-460. doi: 10.1111/j.1467-

8624.2011.01730.x

Tomasello, M. (1999). The Cultural Origins of Human Cognition. Cambridge, MA: Harvard University Press.

Uleman, J. S. (1999). Spontaneous versus intentional inferences in impression formation. In Y. Chaiken \& S. Trope (Eds.), Dual-Process Theories in Social Psychology (pp. 141160). New York, NY: The Guildford Press

Wagenmakers, E. J., Love, J., Marsman, M., Jamil, T., Ly, A., Verhagen, J., . . Morey, R. D. (2017). Bayesian inference for psychology. Part II: Example applications with JASP. Psychon Bull Rev. doi: 10.3758/s13423-017-1323-7 
Visual Perspective Taking

Wagenmakers, E. J., Marsman, M., Jamil, T., Ly, A., Verhagen, J., Love, J., . . Morey, R. D. (2017). Bayesian inference for psychology. Part I: Theoretical advantages and practical ramifications. Psychon Bull Rev. doi: 10.3758/s13423-017-1343-3

Wang, H., Callaghan, E., Gooding-Williams, G., McAllister, C., \& Kessler, K. (2015). Rhythm makes the world go round: An MEG-TMS study on the role of right TPJ theta oscillations in embodied perspective taking. Cortex, 75, 68-81. doi: 10.1016/j.cortex.2015.11.011

Wetzels, R., \& Wagenmakers, E. J. (2012). A default Bayesian hypothesis test for correlations and partial correlations. Psychon Bull Rev, 19(6), 1057-1064. doi: 10.3758/s13423012-0295-x 